\title{
URANS Studies of Hydrodynamic Performance and Slamming Loads on High-Speed Planing Hulls in Calm Water and Waves for Deep and Shallow Conditions
}

\author{
S. Maysam Mousaviraad, Zhaoyuan Wang, Frederick Stern ${ }^{*}$ \\ IIHR-Hydroscience \& Engineering, The University of Iowa, Iowa City, IA 52242-1585, USA \\ * Corresponding author. Tel.: +1 319335 5215; fax: +1 319335 5238; E-mail: frederick- \\ stern@uiowa.edu
}

\begin{abstract}
URANS capability for hydrodynamic performance and slamming of high speed planing crafts are assessed, using metrics specified for naval applications. Wedge drop validation studies using two different solvers, one single-phase and the other two-phase, shows good agreement with experimental data for time history of pressure gauges. Planing hull validation studies are carried out using the historical benchmark experiments of Fridsma. Simulation conditions include calm water in deep and shallow conditions with fixed and free to sinkage and trim motions, as well as regular and irregular head waves in deep water free to heave and pitch motions. For simulations in calm deep water free to sinkage and trim, grid studies show that refined grid density on the hull, especially over the spray root area, chines, and transom stern are necessary for accurate solutions. Detailed verification and validation studies are carried out with satisfactory results since monotonic convergence and validation are achieved for most of the variables. Additional assessment metrics are studied including
\end{abstract}


wave rise, hull pressure distribution, surface streamlines, existence of porpoising, and main spray trajectory. The results are compared with empirical expressions with reasonably good agreement except for main spray trajectory. Resolving the details of the spray flow is beyond the scope of the current work since finer grid resolution and/or more advanced free surface modeling is required. For simulations in calm deep water with fixed sinkage and trim, the assessment metrics include drag and lift forces, pitch moment, drag-lift ratio, and center of pressure. The results agree well with empirical expressions. For simulations in shallow water, similar studies are carried out and reasonable comparison results are obtained. Seakeeping simulations in regular head waves are carried out and validated with experimental data for response amplitudes and phases, with good agreement. Simulations in irregular head waves are carried out for two different weight configurations and validated against experiments for mean and amplitudes of resistance, heave, pitch, and acceleration. Slamming load analysis is carried out, where both emerging and re-entering slams are detected, although the current experimental data lack slamming pressures for validation. More recent research provides additional studies for calm water motions, slamming pressures, and spray flow trajectory that supports current results.

Keywords: Planing Hulls; URANS CFD 


\section{NOMENCLATURE}

$\Delta$

a

A

$a_{p}$

b

$\mathrm{C} \Delta$

CD

CL

$\mathrm{Cm}$

$\mathrm{C}_{\mathrm{P}}$

$\mathrm{C}_{\mathrm{t}}$

$\mathrm{C}_{\mathrm{v}}$

D

DR

E

Em

EV

$f_{e}$

Fr

Frh

$\mathrm{h}$

$\mathrm{H}$ vertical force component, lift (weight)

wave amplitude

wetted area

wave amplitude associated to most probable condition (irregular wave)

beam of planing surface

load coefficient, $\Delta / \mathrm{wb}^{3}$

drag coefficient, $\mathrm{R} /\left(1 / 2 \rho v^{2} \mathrm{~b}^{2}\right)$

lift coefficient, $\Delta /\left(1 / 2 \rho v^{2} b^{2}\right)$

moment coefficient, $M /\left(1 / 2 \rho v^{2} b^{3}\right)$

distance of center of pressure measured along keel forward of transom $(/ \lambda b)$

total resistance coefficient, $\mathrm{R} /\left(1 / 2 \rho \mathrm{Av}^{2}\right)$

speed coefficient, $\mathrm{v} / \mathrm{Vgb}$

Data value

Dynamic Range (for data values)

error value

empirical value

Expected Value

encounter frequency

Froude number based on length

Froude number based on depth

water depth

wave height 


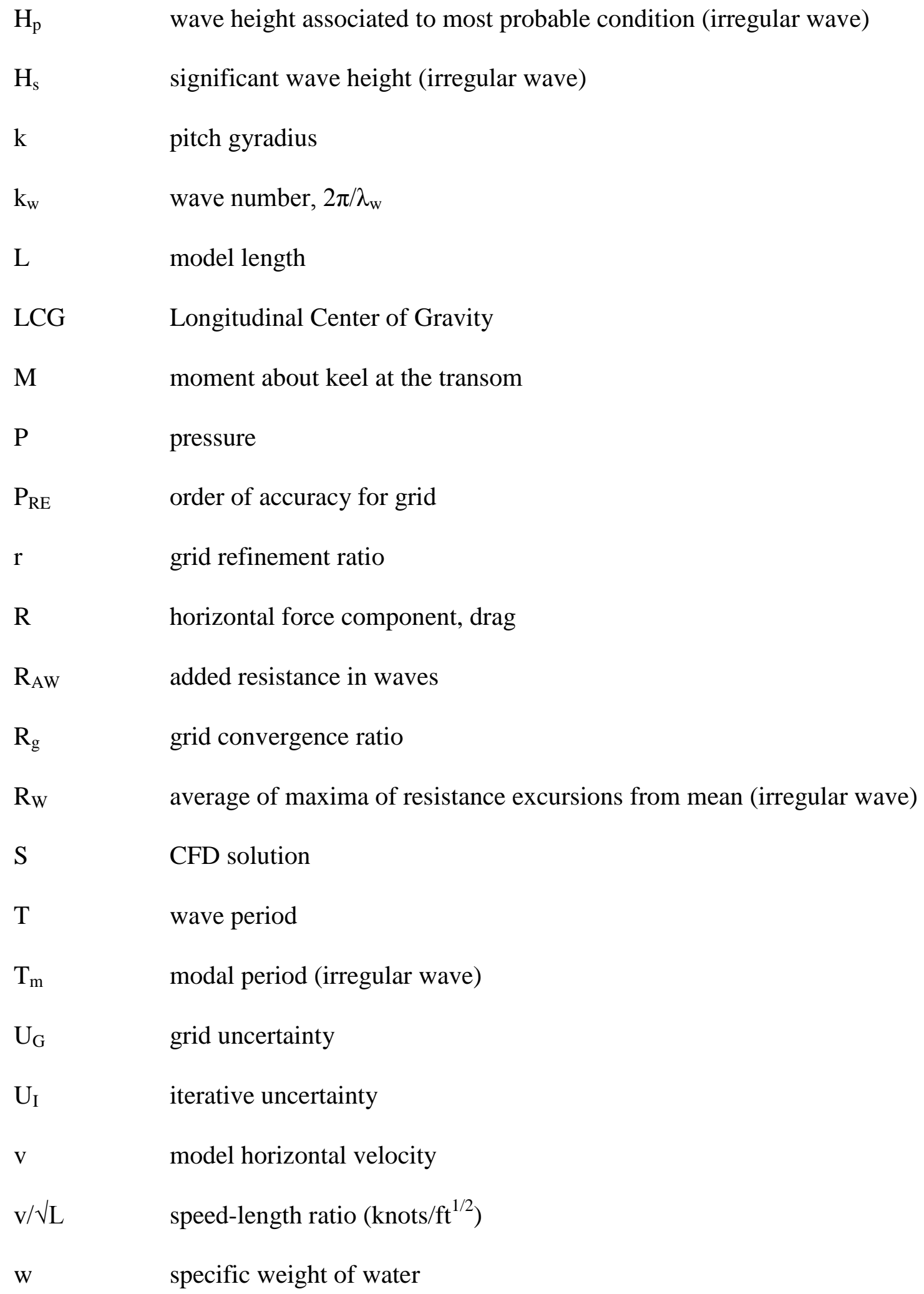




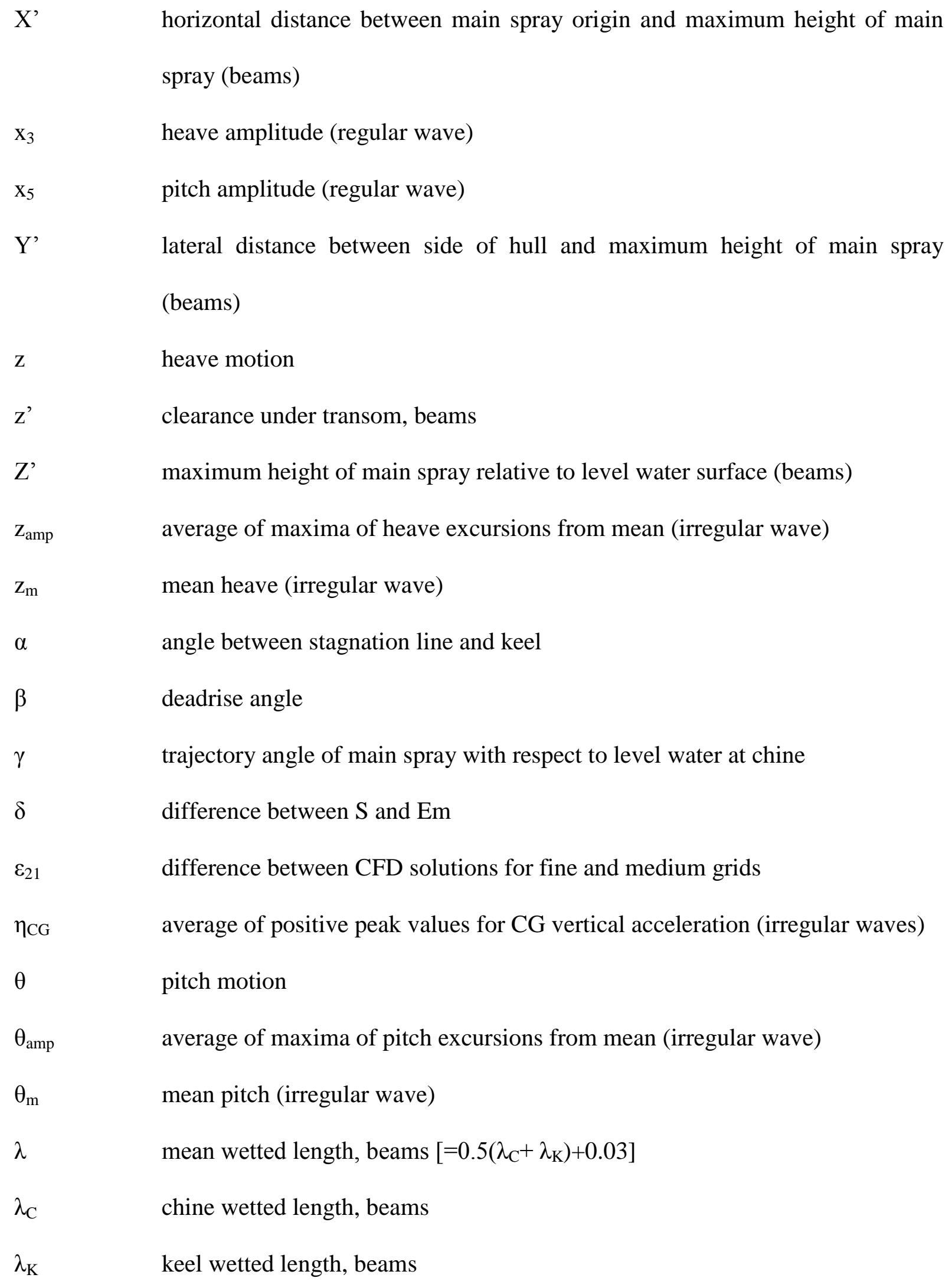




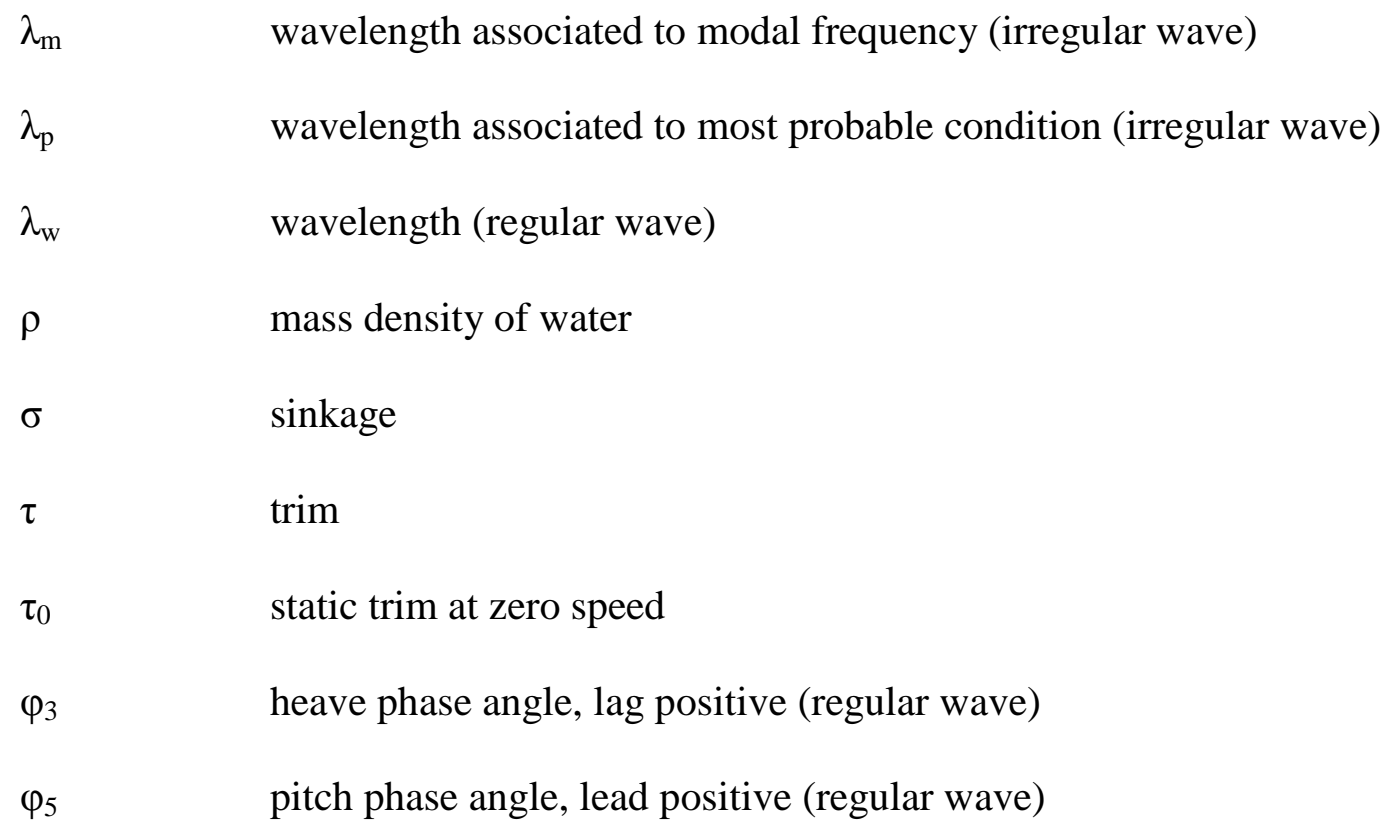




\section{INTRODUCTION}

There is a great interest in very high speed planing crafts. Impact loads due to slamming are one of the critical design issues. Typically, empirical methods have been used for hydrodynamic and stability evaluations of planing vessels [1-3]. Theoretical methods have also been used beginning with the Von Karman model [4] for the problem of 2D wedge drop and extending to the most recent model [5] for 3D steady planing surfaces. Potential flow solvers have been used both for calm water and seakeeping behavior of planing hulls [e.g. 6, 7]. RANS simulations are carried out to predict the forces and moment acting on simple constant deadrise prismatic planing surfaces [8] and are recently extended for stepped hulls with partially ventilated bottom [9]. The grid design and topology and appropriate refinements were found very important in obtaining reasonable agreement with experimental data. Validation studies are carried out for wedge drop and calm deep water free to sinkage and trim for a prismatic geometry using the Euler code NFA [10]. Cartesian grids are used with $805 \mathrm{M}$ grid points for wedge drop and $151 \mathrm{M}$ grid points for calm deep water simulations. Computational fluid dynamic (CFD) simulations of littoral combat ships in head waves equivalent to Sea State 5 are carried out for slamming loads assessments [11]. Unsteady Reynolds averaged Navier-Stokes (URANS) simulations of high-speed Delft catamaran in irregular head waves equivalent to Sea State 6 at $\mathrm{Fr}=0.5$ are carried out using CFDShip-Iowa and slamming loads are analyzed including statistical study of slam events [12].

The objective of current research is to assess CFD capability for challenging application of high-speed planing hull, based on metrics specified for naval applications, using the CFDShip-Iowa solver. Wedge drop validation studies are carried out as a preliminary step to planing hull studies. Verification and validation (V\&V) studies are carried 
out using the historical benchmark experiments of Fridsma $[13,14]$. Simulations are for captive conditions and include calm water in deep and shallow conditions with fixed and free to sinkage and trim motions, as well as regular and irregular head waves in deep water free to heave and pitch motions. Slamming studies are carried out for simulations in waves, although the current experimental data lack slamming pressures for validation. More recent research as discussed in Section "Conclusions and Future Work" provides additional studies for calm water motions and slamming pressures that supports current results.

\section{VALIDATION METRICS AND BENCHMARK DATA}

A systematic process for evaluating the accuracy of hydrodynamic tools for the assessment of small high performance planing crafts is provided to the authors by their navy collaborators (personal communication with Christine Schleicher of NSWCCD Det Norfolk, July 23, 2012). The process involves several phases. The first phase is documenting the physical assumptions made in developing the hydrodynamic analysis tool. Second phase involves computations for conditions in which physics is well known such as flat plate and wedge drop. The metrics for a flat plate planing surface include wave rise and lift coefficient to be compared against values in [1]. For wedge drop, the metric is comparison of pressure distribution against static prismatic wedge experiments such as [15]. The third phase involves computations for generic planing hulls and comparison with model test results, such as [13]. A list of metrics is provided for calm water, as summarized below in this Section, and used as analysis method for current assessment studies. The fourth phase is identified as progression to computations for a full scale craft, and comparisons with full scale experimental results if 
available. The current study covers the first three phases, while the fourth phase will be included in future research.

For calm deep water free to sinkage and trim simulations, resistance, sinkage, and trim curves are compared with the experimental fluid dynamic (EFD) data and the parametric equations by Savitsky [1]. The wave rise is calculated and compared with the empirical expression [1]:

$$
\lambda_{K}-\lambda_{C}=\frac{b}{\pi} \frac{\tan \beta}{\tan \tau}
$$

Hull pressure distributions and surface streamlines are plotted for each simulation identifying the stagnation lines and the spray edge lines and confirming assumptions of [1] that the pressure area is aft of the spray root and that the spray area only contributes to drag. The spray trajectory as it leaves chine is studied and the maximum main spray height as well as transverse and longitudinal location of the maximum spray height are identified and compared with the equations developed in [16]:

$$
\begin{aligned}
& \alpha=\tan ^{-1}\left(\frac{\pi}{2} \frac{\tan \tau}{\tan \beta}\right) \\
& \gamma=\alpha+\tan ^{-1}\left[\left(1-\frac{2}{\pi}\right) \sin \alpha \tan \beta\right] \\
& \mathrm{Z}^{\prime}=\frac{C_{v}{ }^{2}}{2} \sin ^{2} \gamma \\
& \mathrm{X}^{\prime}=C_{v}{ }^{2} \sin \gamma \cos \gamma \cos \alpha \\
& \mathrm{Y}^{\prime}=C_{v}{ }^{2} \sin \gamma \cos \gamma \sin \alpha
\end{aligned}
$$


The occurrence of porpoising phenomenon is evaluated and compared with empirical porpoising limits in [1]. The center of pressure is determined and compared to the empirical value [1]:

$$
C_{P}=0.75-\frac{1}{5.21 \frac{C_{v}^{2}}{\lambda^{2}}+2.39}
$$

Other analysis methods used in current studies for calm water free to sinkage and trim include V\&V studies following the detailed procedures explained in [17].

For calm deep water with fixed sinkage and trim simulation, the results for drag and lift forces and pitch moment are compared with empirical expressions in [2]. Analyses are conducted for drag-lift ratio and center of pressure following [1].

For calm shallow water with fixed sinkage and trim simulations, the results for the ratio of lift and drag force and pitch moment to calm deep water simulations are compared with EFD data and empirical expressions in [3] including collapsing into linear correlations. Also the results for drag-lift ratio plotted against speed coefficient and trim angle and for longitudinal location of the center of pressure are compared with empirical curves from [1].

For calm shallow water free to sinkage and trim simulations the curves for resistance, sinkage and trim ratios vs. Frh are compared with EFD data.

The last calm water validation metric is computations of roll moments for a fixed roll case to be validated against experiments in [18]. This metric is not included in the current study, and will be considered in future research.

For rough water, specific validation metrics are not provided, but it is recommended that a similar step by step approach is used based on cases experimentally tested by Fridsma 
[14]. The validation metrics and analysis methods for regular and irregular wave studies are developed by the authors as follows.

For regular head waves, the analysis methods include transferring the time history of the forces and motions into the frequency domain to obtain the amplitudes and phases. The plots for transfer functions/response amplitude operators (RAOs) and phases are then validated against experiments.

For irregular head waves, convergence studies are conducted based on running mean and running root mean square (RMS) of resistance and motions. Statistical and slamming loads studies are conducted following the procedures explained in [12]. Fast Fourier transform (FFT) analysis is applied to compute amplitudes in the encounter frequency domain. For each mean-crossing period, the associated mean, root mean square of deviations from mean, and amplitude are identified and used for validation studies. Expected value (EV), standard deviation (SD) and cumulative distribution function (CDF) of relevant outputs are also evaluated. The analysis method and terminology for slamming loads follow the guidelines by ABS [19], as described herein. In order to detect the slamming loads, the time-history of pressure is studied at pressure probes. Slamming loads are detected on time histories as pressure jumps with threshold value of $2 \mathrm{kPa}$. If the jump is negative, it is defined as emerging slamming load, whereas a positive jump identifies re-entering slamming load.

Benchmark experimental data used in the current study are as follows. For wedge drop, advanced experiments are performed recently at Naval Surface Warfare Center Carderock Division (NSWCCD) with high frequency pressure gauges and structural element arrays to measure the pressure field both spatially and temporally [15]. The authors have obtained the time history data through private communications with Dr. Allen Engle at 
NSWCCD. The wedge deadrise angle was 10 degrees with total weight of 165 pounds and drops were performed from 5 different heights of 2, 4, 6, 8, and 10 inches.

Constant deadrise planing hull data for calm water resistance, sinkage and trim as well as seakeeping in regular head waves are provided in the experiments of Fridsma [13]. The experiments were designed to define the effects of deadrise, trim, loading, speed, length-beam ratio, and wave proportions on the added resistance, on heave and pitch motions, and on impact accelerations at the bow and center of gravity.

Calm shallow water with fixed sinkage and trim experiments are conducted in [3] and empirical correlations are presented to compliment the calm deep water empirical formulations in [2].

Calm shallow water free to sinkage and trim experiments are carried out for constant deadrise planing hulls based on Series 62 geometry [20]. Tests are conducted over a complete speed range $(\mathrm{Frh}=0.5-3.5)$ with varying $\mathrm{LCG}$ and $\mathrm{h} / \mathrm{L}$ values of $0.18,0.28$, and 0.48 .

Irregular waves experiments are carried out [14] including a systematic study of the effects of deadrise, trim, loading, speed, length-beam ratio, bow section shape and sea state. The added resistance, heave and pitch motions, and impact accelerations at the bow and center of gravity were measured. The irregular waves were generated based on PiersonMoskowitz spectra.

\section{COMPUTATIONAL METHODS}

\subsection{CFDSHIP-IOWA V4.5}

The single-phase level-set solver CFDShip-Iowa V4.5 is an incompressible URANS/DES solver designed for ship hydrodynamics [21]. The equations are solved in an 
inertial coordinate system, either fixed to a ship or other frame moving at constant-speed or in the earth system. Blended $\mathrm{k}-\varepsilon / \mathrm{k}-\omega$ is used for turbulence model, and curvilinear dynamic overset grids for 6DOF ship motions. Incompressibility is enforced by a strong pressure/velocity coupling, achieved using either PISO or projection algorithms. The fluid flow equations are solved in an earth-fixed inertial reference system, while the rigid body equations are solved in the ship system, so forces and moments are projected to perform the integration of the rigid body equations of motion, which are solved iteratively. Initial and boundary conditions are imposed to generate the waves inside the computational domain. Other modeling capabilities include semi-coupled two phase air/water modeling, moving control surfaces, multi-objects, advanced controllers, propulsion models, environmental waves and winds, bubbly flow, and fluid-structure interaction.

Numerical methods include finite difference discretization, with a second-order upwind scheme for the convection terms and second-order centered for the viscous terms. The temporal terms are discretized using a second-order backwards Euler scheme. Since the solver is designed for high-Reynolds number flows, the transport and reinitialization equations are weakly elliptical and thus pentadiagonal line solvers in an alternate-direction-implicit (ADI) scheme are used. A MPI-based domain decomposition approach is used, where each decomposed block is mapped to one processor. The resulting algebraic equation is solved with the PETSc toolkit using block Jacobi incomplete factorization (ILU) pre-conditioners and bi-conjugate gradients stabilized (BiCGStab). All equations of motion are solved in a sequential form and iterated to achieve convergence within each time step. 


\subsection{CFDSHIP-IOWA V6.2}

The CFDShip-Iowa V6.2 [22] is an orthogonal curvilinear grid solver, which is extended from the sharp interface Cartesian grid solver (Version 6.1) for incompressible twophase viscous flows recently developed at the University of Iowa [23]. In this solver, the interface is tracked by a new volume-of-fluid (VOF) method [24]. A ghost fluid methodology is adopted to handle the jump conditions across the interface, where the density and surface tension effect are treated in a sharp way while the viscosity is smeared by a smoothed Heaviside function.

A finite-difference method is used to discretize the governing equations on a nonuniform staggered orthogonal grid, in which the contravariant velocity components are defined at the cell face centers in the coordinate directions, respectively. All other variables are defined at the cell centers. Time advancement of the present study is based on the semiimplicit four-step fractional step method. The diagonal diffusion terms are advanced with the second-order Crank-Nicholson method and the other terms by the second-order explicit Adams-Bashforth method. The pressure Poisson equation is solved to enforce the continuity equation. The convective terms are discretized using the fifth-order Hamilton-Jacobi Weighted-ENO (HJ-WENO) scheme. The other terms are discretized by the second-order central difference scheme. The pressure Poisson equation is solved using a semi-coarsening multigrid solver from the HYPRE library.

The code is parallelized via a domain decomposition (in three directions) technique using the MPI library. All inter-processor communications for ghost cell information exchange are in non-blocking mode. In general, optimal load balance can be achieved except for a small amount of overhead due to interface, which may be unevenly distributed over 
processors. Parallel I/O using MPI2 have been implemented such that all processors read from and write to one single file simultaneously, which is much more effective than one or a few processors receive data from all processors and write to one or a few files and more convenient than every processor writes its own data files.

\section{SIMULATION CONDITIONS}

Wedge drop simulations are carried out for a $10^{\circ}$ deadrise angle wedge with total weight of 165 pounds dropping from a 6 in height. Simulations are carried out with both V4.5 and V6.2 solvers. A 2D orthogonal curvilinear grid is generated for V6.2 simulations and a semi-2D grid with only 5 grid points in the third direction and periodic boundary conditions is designed for V4.5 simulations. The grid information are summarized in Table 1 and the grids are shown in Figure 1. A total of $6.5 \mathrm{M}$ grid points is used for fine simulations using V4.5 while the fine grid for V6.2 has $262 \mathrm{~K}$ grid points. The equation of motion is solved in both solvers, but different reference frames are used. V6.2 simulations use a non-inertial reference frame in which the wedge body is stationary, and the water and air is moved upward at the initial entry velocity at time zero and the negative of the body acceleration is applied to the external water at next time steps. V4.5 simulations are performed on an inertial reference frame in which the water is moved upward at a constant velocity equal to the initial entry velocity, and the wedge body is at zero velocity at time zero and is moved according to the body acceleration at next time steps. The analysis method includes comparing the time history of surface pressure at the five probe locations with experimental data. The time history of wedge velocity is also obtained and compared between the two codes. 
Planing hull simulations are carried out with V4.5 solver for the Fridsma geometry, a constant $20^{\circ}$ deadrise angle prismatic hull with $\mathrm{L} / \mathrm{b}=4$. The calm deep water free to sinkage and trim simulations correspond to a very heavy load of $\mathrm{C}_{\Delta}=0.608$. The experimental value for LCG is $60 \% \mathrm{~L}$ from bow. An LCG sensitivity study is carried out as will be discussed in Section 6. Table 2 shows the grids used for the grid studies. The geometry and the overset grid design system are shown in Figure 2 for grid \#8 which has a total of 7.9M grid points. The Cartesian background grid extends enough to the sides and behind the ship $(-1.0<\mathrm{x} / \mathrm{L}<5$; $1.6<y / L<1.6)$ to capture the free surface and wake flows. The water depth is $\mathrm{z} / \mathrm{L}=-1.25$ for deep water simulations, and the top boundary extends to $\mathrm{z} / \mathrm{L}=0.44$. The boundary layer grid is designed to achieve $\mathrm{y}^{+}<1$. Free surface grids are designed to include sufficient points per surface elevations in the range of the current simulations. The free to sinkage and trim simulations are carried out over a speed range at $\mathrm{v} / \sqrt{ } \mathrm{L}=2,3,4,5$, and $6(\mathrm{Fr}=0.59-1.78)$. Calm deep water with fixed sinkage and trim simulations are carried out at $\tau=4^{\circ}, \lambda=2.75$, and $\operatorname{Fr}=1.1$.

Calm shallow water with fixed sinkage and trim simulations are carried out for $\mathrm{h} / \mathrm{L}=0.3,0.19$, and 0.08 with $\tau=4^{\circ}$. Slip boundary condition is used for the bottom wall and the same number of grid points in $\mathrm{z}$ direction as grid\#8 is used for each depth condition. A simulation with no-slip boundary condition is also carried out for the shallowest condition $\mathrm{h} / \mathrm{L}=0.08$. A boundary layer grid with $\mathrm{y}^{+}<1$ is designed near the bottom wall for this simulation. Calm shallow water free to sinkage and trim simulations are carried out at $\mathrm{h} / \mathrm{L}=0.3$ with slip bottom boundary condition. The weight condition is same as calm deep water free to sinkage and trim simulations at $\mathrm{C}_{\Delta}=0.608$ and the adjusted $\mathrm{LCG}$ of $61 \% \mathrm{~L}$ is used. Six different speeds are simulated covering the range of $\mathrm{Fr}=0.47-1.79$ and $\mathrm{Frh}=0.85-3.26$. 
Regular head waves validation is carried out at a heavier weight, $\mathrm{C}_{\Delta}=0.631$. The LCG value of $52.5 \% \mathrm{~L}$ is used for which the EFD calm water dynamic trim is $4^{\circ}$. Note that same LCG as EFD value is used for CFD simulations and no sensitivity study for LCG variations are performed. The background grid is re-distributed for simulations in waves to ensure at least 60 points per wavelength and 20 points per wave height, while the total number of grid points is the same as grid\#8. The simulations are carried out at $\mathrm{v} / \sqrt{ } \mathrm{L}=4(\mathrm{Fr}=1.19)$, for which the vessel is beginning to plane and the dynamic and buoyant forces on the hull are both significant. Most of the parametric study in [13] was carried out at this speed because it is the typical speed in planing craft operations.

Irregular head waves validation studies are carried out at two different weight conditions, $\mathrm{C}_{\Delta}=0.480$ and $\mathrm{C}_{\Delta}=0.384$, and at $\mathrm{v} / \sqrt{\mathrm{L}}=4(\mathrm{Fr}=1.19)$. Calm water validation is carried out for each condition including LCG sensitivity studies. Regular wave simulations corresponding to the most probable condition of irregular waves are carried out before irregular simulations, also including LCG sensitivity studies. As will be discussed in Section 9, the original EFD values of LCG are used for simulations in irregular waves, based on the CFD results of LCG studies in regular waves. Irregular waves are generated in the computational domain by superimposing 32 regular wave components based on Pierson Moskowitz spectrum. The significant wave height in model scale is 6 in $(15.24 \mathrm{~cm})$ for a $3 \mathrm{ft}$ (0.9144 m) model, i.e. $\mathrm{H}_{\mathrm{s}} / \mathrm{L}=0.168$. The modal frequency is $0.5 \mathrm{~Hz}$ in model scale.

\section{2D WEDGE DROP VERIFICATION AND VALIDATION}

The wedge drop validation is used as the first step for planing hull slamming simulations. For the $10^{\circ}$ deadrise angle and drop height of 6 inches, the EFD data show a peak 
pressure value of $11.8 \mathrm{psi}$. The measured pressure time histories show the general trend of rapid ramp-up to peak pressure with relatively slow decay. The results for CFDShip-Iowa V6.2 and V4.5 are shown in Figure 3. Smaller time step and finer grid is required for V6.2 simulations to accurately predict the peak pressure values. For V4.5 the finer grid simulation better predicts the timing especially for the last probe. Overall, fine grid simulations from both codes show very good agreement with experiments for peak pressure magnitudes and pulse duration. Because of the deceleration of the wedge due to the impact with the free surface, the length of time between the final two is greater than that of the preceding peaks which is correctly predicted. Brief incidents of negative pressure before the peak pressure are evident in experiments and in V4.5 simulations. The exact reason is not clear. One possibility is that this may be due to turbulent breakup of the expanding spray root. Alternatively it may be a modeling limitation in CFD and an issue in experiments due to interaction of the jet flow with unsmooth surface of the pressure probe.

The time histories of wedge velocity are plotted in Figure 3 for both simulations. The predicted wedge velocities are very close for the non-inertial V6.2 and the inertial V4.5 simulations. The snapshots of free surface and pressure distributions at the five probe locations are shown in Figure 4. The computed pressure fields are almost the same for the V4.5 and V6.2 simulations. As shown in the figure, more detailed interface structures of the spray root are demonstrated in V6.2 than in V4.5. This is because a more accurate VOF method is used for the interface modeling in V6.2, which has a much better mass conservation property than the level set method as used in V4.5. 


\section{CALM DEEP WATER VERIFICATION AND VALIDATION}

A detailed grid study is conducted for calm deep water free to sinkage and trim at $\mathrm{Fr}=0.89$ and the results are shown in Table 2 . Only trim errors are included since trim was found most sensitive to grid variations, as expected. Different grid designs are used. All designs include a fixed background grid and one or more moving body-fitted grids. For designs A to D, the body fitted grid contains only one grid block, as shown in Figure 2 for design $\mathrm{C}$, but with different distributions of the grid points along the hull. Grids A has almost equally spaced points along the length and along the beam of the model. Grid B has smaller grid spacing at the keel and in the bow area where the spray root is located for the current Fr range. The $2.9 \mathrm{M}$ grid size with design $\mathrm{B}$ achieves the same results as the $6.1 \mathrm{M}$ grid with design A. Grid $\mathrm{C}$ has the same features of grid $\mathrm{B}$, but the spacing is also reduced near the transom. The results show significant reduction in trim prediction error. Grid D is based on grid \#8 with a Cartesian refinement block at the bottom of the model up to almost the chine. The result does not show significant improvement with refinement grid. For design E, multiple overlapping blocks are used for the hull. The hull surface grids overlap each other to provide the best refinement concentrated only in the areas where needed, i.e. the spray root area, the chine, and the transom. The results for this grid design with $16.9 \mathrm{M}$ grid points show the best agreement with EFD. However, the improvement in accuracy of the results is not large enough to justify the computational cost. Therefore systematic grid studies are carried out for design C. Overall, the current studies show that the accuracy of the results depend on the quality of grid distribution. The refinement block did not improve the results, indicating that the additional points should be placed on the hull and not away from it. Also the 
distribution on the hull should be clustered over the fore body where the spray flow forms, and near chines and transom stern where the flow separates from the hull.

Verification and validation results using systematically refined grids with refinement ratio of $r=\sqrt{ } 2$ are shown in Table 3 . The grid sizes range from $7.9 \mathrm{M}$ to $26.4 \mathrm{M}$ grid points. Iterative convergence is achieved since $\mathrm{U}_{\mathrm{I}}$ is at least one order of magnitude smaller than $\varepsilon_{21}$ and is negligible compared to $\mathrm{U}_{\mathrm{G}}$. Monotonic convergence is achieved for all variables with trim being closest to the asymptotic range $\left(\mathrm{P}_{\mathrm{RE}}=1\right)$. Validation studies are carried out for resistance, sinkage, and trim. Based on the definition in [17], validation is achieved when the error value $\mathrm{E}$ is smaller than the validation uncertainty $\mathrm{U}_{\mathrm{G}}$. For resistance, validation is achieved at the interval of $\mathrm{U}_{\mathrm{G}}=3.8 \% \mathrm{~S}_{1}$ with $\mathrm{E}=0.97 \% \mathrm{D}$. For sinkage, validation is not achieved and grid uncertainty and error values are $\mathrm{U}_{\mathrm{G}}=1.4 \% \mathrm{~S}_{1}$ and $\mathrm{E}=9.3 \% \mathrm{D}$. For trim validation is achieved at the interval of $\mathrm{U}_{\mathrm{G}}=6.38 \% \mathrm{~S}_{1}$ with $\mathrm{E}=5.1 \% \mathrm{D}$. Overall, the grid studies confirm that the numerical errors induced by grids are within acceptable range.

EFD trends [13] show that for $\mathrm{V} / \sqrt{\mathrm{L}}=2(\mathrm{Fr}=0.59)$ the buoyancy forces play the major role and there is a significant amount of side-wetting. At $\mathrm{V} / \sqrt{\mathrm{L}}=4(\mathrm{Fr}=1.19)$ the boat is beginning to plane, the dynamic and buoyant forces on the hull are both significant, and some side-wetting still appears at this speed. At $\mathrm{V} / \sqrt{ } \mathrm{L}=6(\mathrm{Fr}=1.78)$ the hull is fully planing, the buoyancy plays only a minor role, and no side-wetting is observed. The resistance curve shows a hump at $\mathrm{Fr}=0.89$ followed by a reduction at $\mathrm{Fr}=1.19$ and slight increase at the higher Fr values. The model starts to rise up at $\mathrm{Fr}=0.89$ and the magnitude of $\mathrm{CG}$ rise increases with speed. Trim is the maximum at $\operatorname{Fr}=1.19\left(6.9^{\circ}\right)$ and decreases to $4.9^{\circ}$ at the maximum $\operatorname{Fr}=1.78$. CFDShip-Iowa results for LCG and grid size variations are shown in Figure 5. The LCG sensitivity studies show that the results, especially for trim, are very sensitive to LCG. 
For example, moving the LCG backward from its original value of $60 \% \mathrm{~L}$ from bow to $61 \% \mathrm{~L}$ (only 0.38 inches adjustment for the 3.2 feet long model), results in trim error improvement from $15.4 \% \mathrm{D}$ to $7.4 \% \mathrm{D}$ at $\mathrm{Fr}=0.89$. The effects of grid size show that increasing the grid points from $7.9 \mathrm{M}$ to $16.9 \mathrm{M}$ reduces the trim error from $7.4 \% \mathrm{D}$ to $4.9 \% \mathrm{D}$ at $\mathrm{Fr}=0.89$.

The validation results for resistance, sinkage, and trim are reported in Table 4 and shown in Figure 5. The results are compared with parametric equations by Savitsky and NFA simulations (not shown in Figure 5). For resistance, Savitsky equations under-predict the total resistance for small Fr and over-predict for large Fr. Both NFA and CFDShip-Iowa overpredict resistance at all Fr and especially for large Fr. EFD shows a small hump at Fr=0.89 which is not predicted by Savitsky or the CFD codes. The average resistance errors for CFDShip-Iowa and NFA are $11.2 \%$ and $10.6 \%$, respectively. Savitsky under-predicts the rise at almost all Fr while NFA under-predicts only at large Fr and CFDShip-Iowa over-predicts at small Fr and under-predicts at large Fr. For large Fr>1 CFDShip-Iowa results are closer to EFD than NFA. The average rise errors over the whole Fr range are $7.1 \%$ for CFDShip-Iowa and $5.4 \%$ for NFA. For trim angles Savitsky agrees best with EFD, while both CFDShip-Iowa and NFA predict the maximum trim angle at $\mathrm{Fr}=0.89$ and under-predict at higher Fr. The average trim errors over the whole Fr range are $13.5 \%$ for CFDShip-Iowa and 9.3\% for NFA. Overall, the average validation errors for all variables and over the whole Fr range are 10.6\% for CFDShip-Iowa and $8.4 \%$ for NFA.

Figure 6 shows the predicted wave rise values which compare very well with the values from Equation (1) for its range of applicability, i.e. $\mathrm{C}_{\mathrm{v}}>2.0$ (Fr $>1$ for current simulation). 
Figure 7 shows the hull pressure contours and surface streamlines showing flow direction along the hull and extent of spray area for CFDShip-Iowa simulations. As discussed in [1], it is observed that the wetted bottom area of a planing hull is divided into a pressure area aft of the spray root line and a spray area forward of the spray root line. It is observed that the pressure values are relatively small in the spray area and the flow along the spray root line is primarily along the direction of the stagnation line.

Figure 8 shows the two distinct spray patterns for planing hulls called the 'whisker' spray and the main spray. The empirical values from Equations (4-6) and the values obtained from current simulations are shown in Figure 9. $X^{\prime}$ is slightly over-predicted while $Y^{\prime}$ and $Z^{\prime}$ are significantly under-predicted. The reason is, as observed in Figure 8, the tail of the main spray is not resolved in current simulations. Perhaps very high grid resolution is required to accurately capture the details of the spray flow with the current level set solver, as was also realized from the wedge drop simulations. However, resolving the details of the spray flow is beyond the scope of the current work.

Porpoising limits from [1] are plotted in Figure 10 and compared with current simulation conditions. The solution time histories show that porpoising does not occur for the current very heavy weight conditions in the speed range simulated, which is consistent with the empirical criteria.

Drag-lift ratios are plotted against speed coefficient and trim angle in Figures 11 and 12 , respectively, for calm deep water with fixed sinkage and trim simulations at $\tau=4^{\circ}$ including comparison with [1]. The predicted values agree closely to the empirical values for both pressure and total drag. 
Figure 13 compares the center of pressure results for the calm deep water with fixed sinkage and trim simulation to the empirical curve from Equation (7) which shows very close agreement.

\section{CALM SHALLOW WATER VALIDATION}

\subsection{VALIDATION FOR FIXED CONDITIONS}

Calm shallow water with fixed sinkage and trim simulations are summarized in Table 5. Experimental data are only available for the first condition, since the majority of the experiments are performed with $\beta=10^{\circ}$ geometry. However, empirical correlations are provided for the whole range of conditions and deadrise angles [3].

EFD trends show that for calm deep water, the forces and the moment are linear when plotted against $\mathrm{C}_{\mathrm{v}}{ }^{2}$ for $\mathrm{C}_{\mathrm{v}}{ }^{2}$ up to 50 . The shallow water results when plotted against $\mathrm{C}_{\mathrm{v}}{ }^{2}$ were linear up to $\mathrm{C}_{\mathrm{v}}{ }^{2}=20$ and from $\mathrm{C}_{\mathrm{v}}{ }^{2}=30$ to 50 with a slightly higher slope, while a non-linear transition between $\mathrm{C}_{\mathrm{v}}{ }^{2}=20$ and 30 was observed. Since most planing hulls operate at or below $\mathrm{C}_{\mathrm{v}}{ }^{2}=20$, the detailed shallow water experiments and empirical correlations are confined to this speed range. It was found that if the water clearance under the hull, one beam forward of the transom, is held constant then the lift force and the pitch moment ratios to those at infinite depth are constant, regardless of the trim, speed, wetted length and depth of water.

Table 6 shows the detailed validation studies against the EFD data and comparison with the empirical correlations. The differences between the correlations and the data are about $3 \%$ for $C_{L}$ and $C_{m}$ and $6 \%$ for $C_{D}$. The errors for CFD predictions are $1.6 \% \mathrm{D}$ for mean wetted length $(\lambda), 8.8 \% \mathrm{D}$ for $\mathrm{C}_{\mathrm{L}}, 1.6 \% \mathrm{D}$ for $\mathrm{C}_{\mathrm{m}}$, and $12.1 \% \mathrm{D}$ for $\mathrm{C}_{\mathrm{D}}$. 
Table 7 and Figure 14 compare the results for calm deep and shallow water simulations with empirical correlations. For deep simulations, the maximum difference is for pitch moment predictions $(9.3 \% \mathrm{Em})$ while the minimum difference is observed for lift force $(2.8 \% \mathrm{Em})$. For the shallow computations, the differences with empirical correlations are generally largest for the very shallow condition $\mathrm{h} / \mathrm{L}=0.08$. The no-slip simulations improve the results for all the parameters reducing the average difference with empirical values from 9.5\% Em to $7.0 \% \mathrm{Em}$. The collapse of the results into linear correlations is shown in Figure 14 where the CFD simulation results also follow the linear trends with good agreement. The free surface profiles are shown in Figure 15 for deep, $\mathrm{h} / \mathrm{L}=0.3$, and $\mathrm{h} / \mathrm{L}=0.08$ with no-slip bottom boundary condition simulations.

\subsection{FREE TO SINKAGE AND TRIM SIMULATIONS}

EFD trends for calm shallow water free to sinkage and trim experiments for Series 62 planing geometry show that over the range of speed and water depth conditions the data for shallow to deep water ratios collapse for all LCG values [20]. Significant increase in trim, draft and resistance is observed at speeds equal to or less than the critical speed (Frh=1), but at supercritical speeds, there is appreciable reduction in resistance and draft compared to deep water. This phenomenon is governed primarily by Frh and secondarily by $\mathrm{h} / \mathrm{L}$.

Figure 16 compares the CFD results for calm deep and shallow water simulations with EFD data for Series 62. For calm deep water condition, the resistance $(\mathrm{R} / \Delta)$ values are generally larger for the prismatic geometry than the Series 62 . The rise and trim angles are slightly larger at larger Fr for the prismatic geometry. 
The shallow to deep ratios are also compared in Figure 16 for both geometries. Generally, very similar trends are observed. At the critical speed (near Frh $=1.0)$ the water passing under the hull must speed up more than in deep water, causing reduction in the pressure gradient and an increase in resistance with greater sinkage and trim. Also the water will not flow underneath the hull as easily as in deep water and the flow goes around the hull and results in a different wave pattern. Due to the trim sensitive nature of planing hulls, shallowness causes sudden increases in resistance and sinkage. The $R / R_{\infty}$ curves peak at Frh values slightly smaller than 1.0. The magnitude and location of the peak is a function of $\mathrm{h} / \mathrm{L}$, i.e. the larger the $\mathrm{h} / \mathrm{L}$ the smaller the peak and Frh where the peak occurs. For the current simulations for the prismatic geometry with $\mathrm{h} / \mathrm{L}=0.3$, the peak occurs at about the same Frh and its magnitude is close to that of Series 62 experiments with $\mathrm{h} / \mathrm{L}=0.29$. The curves drop below 1.0 in the supercritical region representing a power savings. The reason is that the local flow contributes to greater dynamic lift, which is also shown by the sinkage curves. The $\sigma / \sigma_{\infty}$ curves are more complicated and generally show a peak at a Frh smaller than 1.0, then a sudden drop after the critical speed followed by another peak at a larger Frh. The curve for the current simulations for the prismatic geometry with $\mathrm{h} / \mathrm{L}=0.3$ follows the same trend and almost the same magnitudes as the Series 62 experiments with $\mathrm{h} / \mathrm{L}=0.29$. The $\tau / \tau_{\infty}$ curves peak at a Frh slightly smaller than 1.0 , similar to the resistance curves. The current simulation results are again in the same range as their corresponding experimental data.

\section{REGULAR HEAD WAVES VALIDATION}

EFD trends [13] for seakeeping tests show that the linearity of the results with wave amplitude is in general a function of speed and wavelength. Accelerations and added 
resistance in waves are generally non-linear at all speeds, being power functions of the wave height with the actual power subject to speed and model configuration. In the displacement range of speeds $(\mathrm{V} / \sqrt{\mathrm{L}}<2 ; \mathrm{Fr}<0.59)$ motions are linear with wave height over all wavelengths. In the planing range the motions again vary according to some power law of the wave height.

Heave and pitch natural frequencies are predicted by carrying out a zero speed CFD simulation with an initial heave and pitch imposed at time zero. The heave and pitch natural frequencies were predicted to be 1.94 and $1.92 \mathrm{~Hz}$ model scale, respectively.

Table 8 shows the conditions for seakeeping simulations and the validation results. The $\lambda_{\mathrm{w}} / \mathrm{L}$ values range from 1.0 to 6.0 and the resonant frequency corresponds to a $\lambda_{\mathrm{w}} / \mathrm{L}$ of almost 4.0 for the current speed. The results for transfer functions and phases are shown in Figure 17. Very good agreement with the experimental data is obtained. The motion transfer functions reach maximum near the resonant frequency, around $\lambda_{\mathrm{w}} / \mathrm{L}=4.0$. The motion phases, however, peak at a different frequency around $\lambda_{\mathrm{w}} / \mathrm{L}=2.0$. For most of the cases tested in the experiments, the motion phases peaked at a frequency of almost one-half the resonant frequency, which is different from a displacement ship [13].

\section{IRREGULAR HEAD WAVES VALIDATION}

\subsection{EFD TRENDS}

The EFD trends [14] show that at $\mathrm{V} / \sqrt{ } \mathrm{L}=2(\mathrm{Fr}=0.59)$ added resistance in waves and acceleration levels are relatively low, while pitch motions are large. The heave and pitch motions oscillate about mean levels which are identical to the running values obtained in smooth water. At $\mathrm{V} / \sqrt{ } \mathrm{L}=4(\mathrm{Fr}=1.19)$, the mean heave and trim are generally close to their 
static values in calm water, while the mean value of resistance is larger than calm water resistance, with added resistance reaching its maximum at this speed. At $\mathrm{V} / \sqrt{\mathrm{L}}=6(\mathrm{Fr}=1.78)$ the planing boat moves across the tops of the waves for the most part, but rebounds violently in the higher and longer waves. Excessive spray and high accelerations are also associated with performance at this speed. Significant shifts in the mean heave and trim levels are observed in the highest sea states. The effects of significant wave height increased resistance, motions, and accelerations. The higher deadrise angles were found advantageous at higher speeds where deadrise accounts for substantial attenuation of the motions and accelerations and decreased added resistance. The disadvantage of larger deadrise angles is increased calm water resistance at lower speeds. The effects of trim also become more significant with higher speeds where motions and accelerations increase with higher trim angles. Added resistance increases with trim for $\mathrm{V} / \sqrt{\mathrm{L}}<2(\mathrm{Fr}<0.59)$ and decreases at higher speeds. The effects of load (weight) were found to decrease the acceleration levels significantly at all speeds and decrease the motions at planing speeds.

\subsection{CALM WATER AND REGULAR WAVES SIMULATIONS FOR THE}

\section{MOST PROBABLE CONDITIONS}

Table 9 summarizes the conditions for the selected validation simulations which include EFD data for calm water. Similar to calm water validation studies in Section 6, LCG sensitivity studies are conducted for each weight configuration and the results are reported in Tables 10 and 11 . The results show that adjusted LCG simulations give more accurate results for all variables. The required adjustments are from $54.3 \% \mathrm{~L}$ to $59 \% \mathrm{~L}$ for heavy weight and from $57.7 \%$ L to $63 \% \mathrm{~L}$ for light weight. 
Regular waves simulations for the most probable condition of the irregular waves are carried out for both original and adjusted LCG values and the results are reported in Tables 12 and 13 for heavy and light weight configurations, respectively. Note that the differences are not error values, but indicative of how far the CFD regular wave results are from the EFD irregular data. The results for heavy configuration show that for mean heave and mean pitch motions, the CFD regular waves results with adjusted LCG are closer to the EFD values for irregular conditions, while for added resistance and amplitudes of forces, motions, and acceleration, the CFD regular waves results with adjusted LCG are further away from EFD irregular data. Also for light configuration the CFD regular waves results with original LCG are generally closer to the EFD data in irregular waves. The original LCG values are therefore used for the CFD irregular validation simulations.

\subsection{STATISTICAL ANALYSIS AND VALIDATION STUDIES}

Figure 18 shows the spectrum for the incoming waves and the reconstructed waves using the superposition of the 32 components.

Iterative convergence studies are conducted and the results for the first 25 modal periods are shown in Figure 19, although up to 100 modal periods are simulated for both heavy and light weight configurations. More details of the statistical convergence studies are included in Table 14. The EV of resistance is smaller for light weight configuration than for heavy weight, while the EV of rise and trim are larger for light weight configuration. The $\mathrm{SD} \% \mathrm{EV}$ of resistance is much larger for light weight configuration than for heavy weight, while the SD\%EV of motions are very similar for heavy and light weight configurations. The 
probability distribution functions (PDF) are also plotted in Figure 20. The PDF is much narrower for $\mathrm{Ct}$ than for heave and pitch motions.

Validation results for irregular simulations with both heavy and light weight configurations are summarized in Table 15. For added resistance the prediction error is larger for light weight than heavy weight, while for resistance amplitude the errors are similar at about $10 \%$ D. For motions, validation errors are larger for heavy weight than light weight while for acceleration the errors are almost the same at about $1 \% \mathrm{D}$. The $\mathrm{CG}$ vertical acceleration is more severe for light weight configuration, with amplitude of acceleration of almost $1.0 \mathrm{~g}$, being $45 \%$ larger than heavy weight.

\subsection{SLAMMING LOAD ANALYSIS}

There are no EFD data for slamming loads. CFD studies initially considered both bow and stern probes, but the results showed that no stern slamming was detected. This is expected since generally slamming in the bow area is more severe in head wave, while slamming in the stern area is more critical in following sea. Also examinations of the hull pressure distribution during the slamming events showed that the slam pressures are the highest at the keel. The locations of the final three bow probes in CFD slamming studies are shown in Figure 21, along with the time histories of pressures. For statistical studies, probe B2 is chosen since it has the largest number of events and the largest loads. A magnified view is shown for B2, in which the re-entering and emerging peaks are evident for each slam.

Table 16 shows the results for waves producing slams, and slamming loads on probe B2. The analyses are conducted over 37 modal wave periods for heavy weight and 61 wave periods for light weight. The slamming waves have slightly larger period and amplitude for 
heavy weight configuration. The average for the total number of slams per wave period is 1.05 for heavy weight and 2.3 for light weight simulations. Almost the same number of emerging and re-entering slams are detected for both weight configurations. The absolute EV for emerging pressure magnitude is $18.4 \mathrm{KPa}$ for heavy weight and $16.6 \mathrm{KPa}$ for light weight. For re-entering slam, the EV for pressure magnitude is much larger for light weight (45.8 $\mathrm{KPa}$ ) than for heavy weight $(31 \mathrm{KPa})$. The SD\%EV values are smaller for emerging (average 4.8\%) than re-entering slams (average 51.1\%). The maximum emerging slam pressures are almost equal at about $28.5 \mathrm{KPa}$, while for re-entering slams the maximum pressure values reach up to $51.7 \mathrm{KPa}$ for heavy weight and 167.5 for light weight configurations. The PDF for slamming pressure is also shown in Figure 20 which shows a peak at negative pressure values for emerging and another peak at positive pressure values for re-entering slams.

\section{CONCLUSIONS AND FUTURE WORK}

URANS capability for hydrodynamic performance and slamming of high speed planing crafts are assessed, based on metrics specified for naval applications, using the CFDShip-Iowa solver. Wedge drop validation is carried out for a $10^{\circ}$ deadrise angle wedge using two different solvers, the single phase level set solver CFDShip-Iowa V4.5 and the two phase VOF solver CFDShip-Iowa V6.2. Very good agreement with experimental data is obtained for time histories of pressures on the surface of the wedge.

Planing hull studies are carried out for the historical benchmark experiments of Fridsma, a constant 20 degrees deadrise prismatic hull. All planing hull simulations are carried out with CFDShip-Iowa V4.5. Simulation conditions include calm water in deep and 
shallow conditions with fixed and free to sinkage and trim motions, as well as regular and irregular head waves in deep water free to heave and pitch motions.

Detailed verification and validation $(\mathrm{V} \& \mathrm{~V})$ studies are conducted for sinkage, trim and resistance in calm deep water. Grid studies included different grid designs and showed that refined distribution on and near the ship hull, especially over the fore body where the spray root is located and near the chine and transom stern where the flow separates from the hull, is required for accurate prediction of planing behavior. Systematic grid studies achieved monotonic convergence, and validation was achieved for resistance and trim, while for sinkage the grid uncertainty was larger than the comparison error.

Validation simulations in calm deep water free to sinkage and trim were carried out over the speed-length ratio of 2 to $6 \mathrm{knots} / \mathrm{ft}^{1 / 2}(\mathrm{Fr}=0.59-1.78)$. CFD results are validated with total average error of $10.6 \% \mathrm{D}$. At planing speeds (Fr>1), CFD slightly over-predicts resistance, and under-predicts sinkage and more significantly trim. Several analyses are carried out as per the assessment metrics defined in Section 2, including wave rise, hull pressure distribution, surface streamlines, and existence of porpoising, with good agreement with empirical expressions. Spray trajectory analysis shows that the tail of the spray flow is not resolved in the current simulations. The authors' more recent research, which uses new experimental data for a different planing geometry, namely USNA, presents similar trends of resistance and motion predictions for CFD results with two different solvers, CFDShip-Iowa and NFA [25]. LCG sensitivity studies showed improvement, consistent with present results. The two-phase flow solver CFDShip-Iowa V5.5 (still under development) with improved volume-of-fluid method, is also used. The results show negligible improvement for resistance and motions, while the extension of the jet spray flow is accurately resolved. In addition, 
recent experimental studies with two different model sizes show discrepancy, especially for trim motions. It is speculated that there might be an experimental issue due to flexibility of the mount. Overall, the errors for calm water motions in the present paper are indicative of the state of the art both computationally and experimentally, and are not superseded but supported by the authors' newer research. Spray flow can produce structural damage to the wings and propellers of seaplanes, increase resistance by impacting the tunnel between the hulls of a planing catamaran, or be blown into the craft making for an uncomfortably wet environment. However, resolving the details of the spray flow does not have significant effects on resistance and motion predictions, and is beyond the scope of the current study.

Deep calm water with fixed sinkage and trim simulations are validated against experiments for drag and lift forces and pitch moment with average $\mathrm{E}=6.2 \% \mathrm{D}$. Analyses are conducted for drag-lift ratio and center of pressure, with good agreement with empirical expressions. Calm shallow water with fixed sinkage and trim validations are carried out at $\tau=4^{\circ}$ over the depth range of $\mathrm{h} / \mathrm{L}=0.08-0.3(\mathrm{Frh}=2.04-4.27)$. The results for mean wetted length, lift and drag forces, and pitch moment are validated against the experiments and the empirical expressions, with average error of $6.0 \% \mathrm{D}$. Calm shallow water free to sinkage and trim simulations are carried out at $\mathrm{h} / \mathrm{L}=0.3$ over the range of $\mathrm{Fr}=0.47-1.79(\mathrm{Frh}=0.85-3.26)$ and the results for sinkage, trim and resistance are plotted with the available experimental data for a Series 62 planing geometry. Similar trends are observed and the range of values are comparable to those of the experimental data at $\mathrm{h} / \mathrm{L}=0.29$.

Seakeeping validation in regular head waves is carried out over a range of wave frequency $(\lambda / L=1-6)$. Transfer functions and phases are validated with average error of less than $2 \%$ DR. Irregular head waves validation for two different weight configurations are 
carried out including calm water validation and regular waves simulations for the most probable condition of the irregular waves for each condition. Irregular wave results are validated with total $\mathrm{E}=9.1 \% \mathrm{D}$ averaged over both weight configurations. Statistical analysis and slamming load analysis are carried out and both emerging and re-entering slams are detected with peak pressure values of up to $167 \mathrm{KPa}$ for a 10 meters full scale boat. The current experimental data lack slamming pressures for validation. However, the authors' more recent research [25] includes experimental data for slamming pressures on USNA planing geometry in regular and irregular waves, with good CFD validation results, that support current results.

Future work will produce new experimental validation data, including local flow such as spray trajectory in calm water and slamming pressures in waves. CFD efforts will include systematic V\&V studies for the wedge drop simulations for both CFDShip-Iowa V4.5 and V6.2 codes. For calm deep water the predictions of the spray trajectory will be improved by using refinement blocks since the current wedge drop simulations identified that very fine grids are necessary to capture details of the spray flow. Also a more advanced free surface flow solver will be implemented to resolve the details of the spray flow. The issue with errors in calm water will be investigated both experimentally and computationally. For irregular waves, the empirical PDFs of resistance, motions, and emerging and re-entering slamming loads will be compared to theoretical models such as Normal, Gamma or Beta distributions through Cramer-Von Mises accuracy. Free running validation studies for resistance and propulsion, seakeeping, course keeping and maneuvering including loads and slamming analysis will be carried out in calm water and regular and irregular seas for deep and shallow conditions using propulsion models and real propulsor simulations. 


\section{ACKNOWLEDGMENTS}

Office of Naval Research under Grant N000141210881 administered by Dr. Robert Brizzolara sponsored this research. Matteo Diez from INSEAN helped tremendously with grid studies for calm deep water simulations. The authors would like to thank Drs. Thomas $\mathrm{Fu}$ and Allen Engle for providing references and helpful discussions and Ms. Christine Schleicher for providing design metrics for validation studies.

\section{REFERENCES}

1. SAVITSKY, D., "Hydrodynamic Design of Planing Hulls", Marine Technology SNAME, 1 (1), 1964.

2. BROWN, P.W., “An Experimental and Theoretical Study of Planing Surfaces with Trim Flaps," Davidson Laboratory Letter Report 1463, April 1971.

3. REYLING, C., "An Experimental Study of Planing Surfaces Operating in Shallow Water," Davidson Laboratory Report SIT-DL-76-1835, Stevens Institute of Technology, Hoboken, New Jersey, 1976.

4. VON KARMAN, T., "The Impact on Seaplane Floats during Landing”, National Advisory Committee for Aeronautics, Technical Notes, 1929.

5. SAVANDER, B.R., SCORPIO, S.M., TAYLOR, R.K., "Steady Hydrodynamic Analysis of Planing Surfaces”, Journal of Ship Research, 46 (4), 248-279, 2002.

7. DE JONG, P., "Seakeeping Behaviour of High Speed Ships: An Experimental and Numerical Study”, PhD diss., Delft University of Technology, 2011. 
6. IAFRATI, A., AND BROGLIA, R., "Comparisons between $2 \mathrm{D}+\mathrm{t}$ potential flow models and 3D RANS for planing hulls hydrodynamics", $25^{\text {th }}$ International Workshop on Water Waves and Floating Bodies (IWWWFB), Harbin, China, May 2010.

8. BRIZZOLARA S., SERRA F., "Accuracy of CFD Codes in the Prediction of Planing Surfaces Hydrodynamic Characteristics," Proceedings of the $2^{\text {nd }}$ International Conference on Marine Research and Transportation (ICM RT 2007), Ischia, 28-30 June 2007.

9. BRIZZOLARA S., FEDERICI A., “CFD Modeling of Planning Hulls with Partially Ventilated Bottom," The William Froude Conference: Advances in Theoretical and Applied Hydrodynamics - Past and Future, Portsmouth, 24-25 Nov. 2010, Royal Institution of Naval Architects, vol. 1, ISBN/ISSN: 978-1-905040-77-3.

10. O’SHEA, T.T., BRUCKER, K.A., WYATT, D., DOMMERMUTH, D.G., AND FU, T.C., "A Detailed Validation of Numerical Flow Analysis (NFA) to Predict the Hydrodynamics of a Deep-V Planing Hull," The Third Chesapeake Power Boat Symposium, Annapolis, Maryland, June 2012.

11. AZCUETA, R., "Steady and Unsteady RANSE Simulations for Littoral Combat Ships," 25 $5^{\text {th }}$ Symposium on Naval Hydrodynamics, St. John's, Canada, 8-13 August 2004.

12. HE, W., DIEZ, M., PERI, D., CAMPANA, E.F., TAHARA, Y., STERN, F., "URANS Study of Delft Catamaran Total/Added Resistance, Motions and Slamming Loads in Head Sea Including Irregular Wave and Uncertainty Quantification for Variable Regular Wave and Geometry," $29^{\text {th }}$ Symposium on Naval Hydrodynamics, Gothenburg, Sweden, 26-31 August 2012. 
13. FRIDSMA, G., "A Systematic Study of the Rough-Water Performance of Planing Boats," Davidson Laboratory Report 1275, Stevens Institute of Technology, Hoboken, New Jersey, 1969.

14. FRIDSMA, G., "A Systematic Study of the Rough-Water Performance of Planing Boats: Irregular waves - Part II," Davidson Laboratory Report SIT-DL-71-1495, Stevens Institute of Technology, Hoboken, New Jersey, 1971.

15. JIANG, M., LIEN, V., LESAR, D., ENGLE, A., AND LEWIS, R., “A Validation of Various Codes Using Hydrodynamic Wedge Impact Data," Proceedings of the ASME $31^{\text {th }}$ International Conference on Offshore Mechanics and Arctic Engineering (OMAE2012), Rio de Janeiro, Brazil, June 10-15, 2012.

16. SAVITSKY, D.; MORABITO, M.; "Origin and Characteristics of the Spray Patterns Generated by Planing Hulls," Davidson Laboratory Report SIT-DL-10-1-2882, Stevens Institute of Technology, Hoboken, New Jersey, January, 2010.

17. XING, T. AND STERN, F., "Factors of safety for Richardson extrapolation," Journal of Fluids Engineering, 132(6), 2010.

18. JUDGE, C.Q., "Static and Dynamic Forces and Wetted Lengths for a Planing Hull Model Forced in Roll," The Third Chesapeake Power Boat Symposium, Annapolis, MD, June 15-16, 2012.

19. ABS (AMERICAN BUREAU OF SHIPPING), "Slamming Loads and Strength Assessment for Vessels, ABS guide”, 2011.

20. TORO, A.I., "Shallow-Water Performance of a Planing Boat," Presented at south-east section of SNAME meeting, April 1969. 
21. HUANG, J., CARRICA, P., STERN, F., "Semi-coupled air/water immersed boundary approach for curvilinear dynamic overset grids with application to ship hydrodynamics," International Journal Numerical Methods Fluids, 58, 591-624, 2008.

22. SUH, J., YANG, J., AND STERN, F., "The effect of air-water interface on the vortex shedding from a vertical circular cylinder," Journal of Fluids and Structures, 27 (1), 1-22, 2011.

23. YANG, J. AND STERN, F., "Sharp Interface Immersed-Boundary/Level-Set Method for Wave-Body Interactions,” Journal of Computational Physics, 228, 6590-6616, 2009.

24. WANG, Z., YANG, J., STERN, F., "A new volume-of-fluid method with a constructed distance function on general structured grids," Journal of Computational Physics, 231, 3703-3722, 2012.

25. FU, T.C., BRUCKER, K.A., MOUSAVIRAAD, S.M., IKEDA, C.M., LEE, E.J., O’SHEA, T.T., WANG, Z., STERN, F., and JUDGE, C.Q., “A Computational Fluid Dynamics Study of the Hydrodynamics of High-Speed Planing Craft in Calm Water and Waves," $30^{\text {th }}$ Symposium on Naval Hydrodynamics, Hobart, Tasmania, Australia, 2-7 November 2014. 
Table 1- Grids and time steps used for wedge drop simulations

\begin{tabular}{|c|c|c|c|c|}
\hline \multicolumn{2}{|c|}{} & Grid Dimension & Total Grid Size & Time Step \\
\hline \multirow{2}{*}{ V4.5 } & Coarse & $256 \times 2582 \times 5$ & $3.3 \mathrm{M}$ & $40 \mathrm{kHz}$ \\
\cline { 2 - 5 } & Fine & $256 \times 5122 \times 5$ & $6.5 \mathrm{M}$ & $40 \mathrm{kHz}$ \\
\hline \multirow{2}{*}{ V6.2 } & Coarse & $256 \times 256$ & $65 \mathrm{~K}$ & $40 \mathrm{kHz}$ \\
\cline { 2 - 5 } & Fine & $256 \times 1024$ & $262 \mathrm{~K}$ & $125 \mathrm{kHz}$ \\
\hline
\end{tabular}

Table 2- Grid studies for Fridsma planing hull calm deep water free to sinkage and trim at $\mathrm{Fr}=0.89$. Red: systematic refinement with $\mathrm{r}=2^{1 / 2}$

\begin{tabular}{|c|c|c|c|}
\hline Grid Design & Grid \# & Grid Size & Trim Error (E\%D) \\
\hline \multirow{3}{*}{ A (almost equally spaced) } & 1 & $2.6 \mathrm{M}$ & 10.4 \\
\cline { 2 - 4 } & 2 & $3.9 \mathrm{M}$ & 9.4 \\
\cline { 2 - 4 } & 3 & $6.1 \mathrm{M}$ & 8.1 \\
\cline { 2 - 4 } & 4 & $10.6 \mathrm{M}$ & 6.9 \\
\hline \multirow{2}{*}{ B (smaller at keel and bow) } & 5 & $2.9 \mathrm{M}$ & 8.1 \\
\cline { 2 - 4 } & 6 & $3.9 \mathrm{M}$ & 7.3 \\
\hline \multirow{3}{*}{ C (smaller at stern) } & 7 & $4.0 \mathrm{M}$ & 6.7 \\
\cline { 2 - 4 } & 8 & $7.9 \mathrm{M}$ & 5.8 \\
\cline { 2 - 4 } & 9 & $14.0 \mathrm{M}$ & 5.4 \\
\cline { 2 - 4 } & 10 & $26.4 \mathrm{M}$ & 5.1 \\
\hline D (Refinement Block) & 11 & $19.3 \mathrm{M}$ & 5.5 \\
\hline E (Overset Grid Design) & 12 & $16.9 \mathrm{M}$ & 5.0 \\
\hline
\end{tabular}

Table 3- V\&V results for calm deep water free to sinkage and trim at $\mathrm{Fr}=0.89$

\begin{tabular}{|c|c|c|c|c|c|c|c|}
\hline Parameter & Grids & $\mathrm{r}$ & $\mathrm{U}_{\mathrm{I}} / \varepsilon_{21}$ & $\mathrm{R}_{\mathrm{g}}$ & $\mathrm{P}_{\mathrm{RE}}$ & $\mathrm{U}_{\mathrm{G}}\left(\% \mathrm{~S}_{1}\right)$ & $\mathrm{E}(\% \mathrm{D})$ \\
\hline Ct & \multirow{3}{*}{$8,9,10$} & \multirow{2}{*}{$2^{1 / 2}$} & 0.06 & 0.78 & 0.71 & 3.8 & 0.97 \\
\cline { 1 - 6 } Sinkage & 0.04 & 0.39 & 2.67 & 1.4 & 9.3 \\
\cline { 1 - 6 } Trim & & & 0.08 & 0.73 & 0.9 & 6.38 & 5.1 \\
\hline
\end{tabular}

Table 4- Validation results for calm deep water free to sinkage and trim simulations over the whole range of Fr on grid\#12 $(16.9 \mathrm{M})$

\begin{tabular}{|c|c|c|c|c|c|}
\hline \multirow{2}{*}{ Speed Ratio } & \multirow{2}{*}{ Fr } & \multicolumn{4}{|c|}{ CFDShip-Iowa V4.5; LCG=61\%L (16.9M) } \\
\cline { 3 - 6 } & & $\begin{array}{c}\text { Resistance } \\
\text { E\%D }\end{array}$ & $\begin{array}{c}\text { Sinkage } \\
\text { E\%DR }\end{array}$ & $\begin{array}{c}\text { Trim } \\
\text { E\%D }\end{array}$ & Avg. \\
\hline 2 & 0.59 & 10.99 & 14.55 & 3.86 & 9.80 \\
\hline 3 & 0.89 & 0.78 & 9.32 & 4.99 & 5.03 \\
\hline 4 & 1.19 & 9.45 & 4.50 & 16.09 & 10.01 \\
\hline 5 & 1.48 & 14.57 & 4.35 & 20.80 & 13.24 \\
\hline 6 & 1.78 & 20.38 & 2.87 & 21.61 & 14.95 \\
\hline Avg. & & 11.23 & 7.12 & 13.47 & 10.61 \\
\hline
\end{tabular}

Table 5 Calm shallow water with fixed sinkage and trim simulation conditions

\begin{tabular}{|c|c|c|c|c|c|c|c|c|}
\hline$F r$ & $C_{v}^{2}$ & $\tau$ & $\lambda$ & Ź & 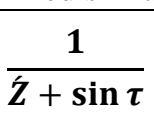 & $\frac{\frac{0.124}{\lambda}+0.116}{\dot{Z}+\sin \tau}$ & $h / L$ & Frh \\
\hline 1.12 & 5.0 & 4.0 & 2.51 & 0.97 & 0.96 & 0.16 & 0.30 & 2.04 \\
\hline \multirow{4}{*}{1.19} & \multirow{4}{*}{5.7} & \multirow{4}{*}{4.0} & \multirow{4}{*}{2.75} & $\infty$ & 0.0 & 0.0 & $\infty$ & 0.0 \\
\hline & & & & 0.95 & 0.99 & 0.16 & 0.30 & 2.17 \\
\hline & & & & 0.51 & 1.74 & 0.28 & 0.19 & 2.73 \\
\hline & & & & 0.06 & 8.0 & 1.29 & 0.08 & 4.27 \\
\hline
\end{tabular}


Table 6 Validation vs. available EFD data for calm shallow water with fixed sinkage and trim

\begin{tabular}{|c|c|c|c|c|c|c|c|c|c|c|}
\hline & & $\beta$ & $\tau$ & $\mathrm{h} / \mathrm{L}$ & $z^{\prime}(/ b)$ & $\mathrm{Fr}$ & $\lambda$ & CL & $\mathrm{Cm}$ & $\mathrm{CD}$ \\
\hline EFD & $\mathrm{D}$ & \multirow{6}{*}{20} & \multirow{6}{*}{4} & \multirow{6}{*}{0.3} & \multirow{6}{*}{0.97} & \multirow{6}{*}{1.12} & 2.51 & 0.140 & 0.180 & 0.018 \\
\hline \multirow{2}{*}{ Empirical } & $\overline{E m}$ & & & & & & 2.51 & 0.135 & 0.175 & 0.019 \\
\hline & $(\mathrm{E} \% \mathrm{D})$ & & & & & & - & 3.34 & 3.09 & 5.94 \\
\hline \multirow{3}{*}{ CFD } & $\mathrm{S}$ & & & & & & 2.55 & 0.128 & 0.177 & 0.020 \\
\hline & E\%D & & & & & & 1.59 & 8.84 & 1.59 & 12.12 \\
\hline & $\delta \%$ Em & & & & & & 1.59 & 5.79 & 1.45 & 5.56 \\
\hline
\end{tabular}

Table 7 Results for calm shallow water with fixed sinkage and trim simulations for different depths at $\mathrm{Fr}=1.19$ and comparison with empirical correlations

\begin{tabular}{|c|c|c|c|c|c|c|c|c|c|c|}
\hline \multirow[b]{2}{*}{$h / L$} & \multirow[b]{2}{*}{ Frh } & \multicolumn{3}{|c|}{$\mathrm{CL}$} & \multicolumn{3}{|c|}{$\mathrm{Cm}$} & \multicolumn{3}{|c|}{$\mathrm{CD}$} \\
\hline & & $\begin{array}{c}\text { Empirical } \\
\text { (Em) }\end{array}$ & CFD & $\delta \% \mathrm{Em}$ & $\begin{array}{c}\text { Empirical } \\
\text { (Em) }\end{array}$ & CFD & $\delta \% \mathrm{Em}$ & $\begin{array}{l}\text { Empirical } \\
\text { (Em) }\end{array}$ & CFD & $\delta \% \mathrm{Em}$ \\
\hline$\infty$ & 0.0 & 0.130 & 0.134 & 2.80 & 0.188 & 0.206 & 9.31 & 0.021 & 0.022 & 6.63 \\
\hline 0.30 & 2.17 & 0.145 & 0.143 & 8.95 & 0.218 & 0.221 & 1.48 & 0.022 & 0.023 & 4.27 \\
\hline 0.19 & 2.73 & 0.157 & 0.153 & 2.55 & 0.225 & 0.235 & 4.41 & 0.023 & 0.023 & 3.03 \\
\hline $\begin{array}{c}0.08 \\
\text { (slip bottom) }\end{array}$ & \multirow[b]{2}{*}{4.27} & \multirow[b]{2}{*}{0.240} & 0.209 & 13.62 & \multirow[b]{2}{*}{0.343} & 0.311 & 9.94 & \multirow[b]{2}{*}{0.029} & 0.027 & 5.09 \\
\hline $\begin{array}{c}0.08 \\
\text { (no-slip } \\
\text { bottom) }\end{array}$ & & & 0.214 & 10.83 & & 0.320 & 6.71 & & 0.028 & 3.59 \\
\hline
\end{tabular}

Table 8- Regular head waves validation results at $\mathrm{Fr}=1.19$ on grid\#8 (7.9M)

\begin{tabular}{|c|c|c|c|c|c|c|c|c|}
\hline \multirow{2}{*}{$\lambda_{\mathrm{w}} / \mathrm{L}$} & \multirow{2}{*}{$\mathrm{f}_{\mathrm{e}}(\mathrm{Hz})$} & \multirow{2}{*}{$\mathrm{H} / \lambda_{\mathrm{w}}$} & \multicolumn{2}{|c|}{ Transfer Functions } & \multicolumn{3}{|c|}{ Phases } \\
\cline { 4 - 9 } & & $\begin{array}{c}\mathrm{x}_{3} / \mathrm{a} \\
\mathrm{E} \% \mathrm{DR}\end{array}$ & $\begin{array}{c}\mathrm{x}_{5} / \mathrm{ak}_{\mathrm{w}} \\
\mathrm{E} \% \mathrm{DR}\end{array}$ & Avg. & $\begin{array}{c}\varphi_{3} \\
\text { E\%DR }\end{array}$ & $\begin{array}{c}\varphi_{5} \\
\text { E\%DR }\end{array}$ & Avg. \\
\hline 1 & 5.75 & $1 / 36$ & 0.97 & 0.18 & 0.58 & 1.82 & 1.54 & 1.68 \\
\hline 1.5 & 4.03 & $1 / 54$ & 4.90 & 0.77 & 2.84 & 1.82 & 1.54 & 1.68 \\
\hline 2 & 3.15 & $1 / 72$ & 1.82 & 0.80 & 1.31 & 3.64 & 1.54 & 2.59 \\
\hline 3 & 2.24 & $1 / 108$ & 0.78 & 5.41 & 3.10 & 1.82 & 4.62 & 3.22 \\
\hline 4 & 1.76 & $1 / 144$ & 1.39 & 1.67 & 1.53 & 1.82 & 1.54 & 1.68 \\
\hline 6 & 1.27 & $1 / 216$ & 1.28 & 0.58 & 0.93 & 1.82 & 1.54 & 1.68 \\
\hline Avg. & & & 1.86 & 1.57 & 1.71 & 2.12 & 2.05 & 2.09 \\
\hline
\end{tabular}

Table 9- Irregular head waves simulation conditions with Pierson Moskowitz wave spectrum for heavy and light weight configurations

\begin{tabular}{|c|c|c|c|c|c|c|c|c|c|c|c|}
\hline \multirow[b]{2}{*}{ Condition } & \multicolumn{4}{|c|}{ Model Configurations } & \multicolumn{4}{|c|}{ Calm Water Conditions } & \multicolumn{3}{|c|}{ Waves Characteristics } \\
\hline & $\begin{array}{l}\text { Weight } \\
\text { coef. }\left(\mathrm{C}_{\Delta}\right)\end{array}$ & $\begin{array}{l}\mathrm{LCG} \\
(\% \mathrm{~L})\end{array}$ & $\begin{array}{l}\text { Gyradius } \\
(\mathrm{k} / \mathrm{L})\end{array}$ & $\begin{array}{c}\text { Static } \\
\text { trim } \\
\left(\tau_{0}, \text { deg }\right)\end{array}$ & $\begin{array}{c}\text { Speed } \\
(\mathrm{V} / \sqrt{L} ; \mathrm{Fr})\end{array}$ & $\begin{array}{l}\text { Resistance } \\
(\mathrm{R} / \Delta)\end{array}$ & $\begin{array}{l}\text { Rise } \\
(\sigma / b)\end{array}$ & $\begin{array}{c}\text { Trim } \\
(\tau, \text { deg })\end{array}$ & $\lambda_{\mathrm{m}} / \mathrm{L}$ & $\begin{array}{c}\mathrm{H}_{\mathrm{s}} / \lambda_{\mathrm{m}} \\
\text { (No. of wave } \\
\text { encounters) }\end{array}$ & $\begin{array}{l}\text { Run time in } \\
\text { model scale } \\
(\mathrm{sec})\end{array}$ \\
\hline $\begin{array}{l}\text { Heavy } \\
\text { Weight }\end{array}$ & 0.480 & 54.3 & 24.9 & -0.6 & \multirow{2}{*}{$4 ; 1.19$} & 0.192 & 0.062 & \multirow{2}{*}{4} & 6.55 & \multirow{2}{*}{$\begin{array}{c}1 / 39 \\
(75-100)\end{array}$} & \multirow{2}{*}{150} \\
\hline $\begin{array}{c}\text { Light } \\
\text { Weight }\end{array}$ & 0.384 & 57.7 & 27.6 & 0.2 & & 0.147 & 0.059 & & 6.55 & & \\
\hline
\end{tabular}

Table 10- Calm water validation and LCG studies for irregular waves simulation condition with heavy weight configuration

\begin{tabular}{|c|c|c|c|c|}
\hline & \multirow{2}{*}{ EFD } & \multicolumn{3}{|c|}{ CFD (E\%D) } \\
\hline & & $\mathrm{LCG}=54.3 \% \mathrm{~L}$ & $\mathrm{LCG}=60 \% \mathrm{~L}$ & $\mathrm{LCG}=59 \% \mathrm{~L}$ \\
\hline 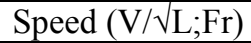 & \multicolumn{4}{|c|}{$4 ; 1.19$} \\
\hline Resistance $(\mathrm{R} / \Delta)$ & 0.192 & 18.45 & 13.78 & 10.38 \\
\hline Rise $(\sigma / \mathrm{b})$ & 0.062 & 35.52 & 22.31 & 10.19 \\
\hline Trim (deg) & 4.0 & 34.65 & 7.57 & 0.8 \\
\hline
\end{tabular}


Table 11- Calm water validation and LCG studies for irregular waves simulation condition with light weight configuration

\begin{tabular}{|c|c|c|c|c|}
\hline & \multirow{2}{*}{ EFD } & \multicolumn{3}{|c|}{ CFD (E\%D) } \\
\cline { 3 - 5 } & & LCG=57.7\%L & LCG=65\%L & LCG=63\%L \\
\hline Speed $(\mathrm{V} / \sqrt{\mathrm{L}} ; \mathrm{Fr})$ & \multicolumn{4}{|c|}{$4 ; 1.19$} \\
\hline Resistance $(\mathrm{R} / \Delta)$ & 0.147 & 36.1 & 10.4 & 11.4 \\
\hline Rise $(\sigma / \mathrm{b})$ & 0.059 & 28.8 & 2.5 & 16.9 \\
\hline Trim $(\mathrm{deg})$ & 4.0 & 34.1 & 16.0 & 2.0 \\
\hline
\end{tabular}

Table 12- Regular waves studies for the most probable condition of irregular waves for heavy weight configuration and comparison with EFD irregular waves results

\begin{tabular}{|c|c|c|c|c|c|}
\hline \multirow[b]{2}{*}{ Parameter } & \multirow[b]{2}{*}{ EFD, Irregular } & \multicolumn{2}{|c|}{$\mathrm{LCG}=54.3 \% \mathrm{~L}$} & \multicolumn{2}{|c|}{$\mathrm{LCG}=59 \% \mathrm{~L}$} \\
\hline & & $\begin{array}{l}\text { CFD, Regular, } \\
\text { Most Probable }\end{array}$ & $\begin{array}{l}\text { Difference } \\
(\mathrm{d} \% \mathrm{D})\end{array}$ & $\begin{array}{l}\text { CFD, Regular, } \\
\text { Most Probable }\end{array}$ & $\begin{array}{c}\text { Difference } \\
(\mathrm{d} \% \mathrm{D})\end{array}$ \\
\hline$\lambda_{\mathrm{p}} / \mathrm{L}$ & \multicolumn{5}{|c|}{2.788} \\
\hline$a_{p} / L$ & \multicolumn{5}{|c|}{0.0545} \\
\hline $\mathrm{H}_{\mathrm{p}} / \lambda_{\mathrm{p}}$ & \multicolumn{5}{|c|}{$1 / 26$} \\
\hline Added Resistance $\left(\mathrm{R}_{\mathrm{AW}} / \Delta\right)$ & 0.085 & 0.155 & 82.35 & 0.167 & 96.47 \\
\hline $\begin{array}{l}\text { Average of Resistance Amp. } \\
\left(\mathrm{R}_{\mathrm{W}} / \Delta\right)\end{array}$ & 0.277 & 0.266 & 3.97 & 0.223 & 19.49 \\
\hline Mean Heave $\left(\mathrm{z}_{\mathrm{m} .} / \mathrm{b}\right)$ & 0.052 & 0.016 & 69.23 & 0.04 & 23.08 \\
\hline Average of Heave Amp. $\left(\mathrm{z}_{\mathrm{amp}} / \mathrm{b}\right)$ & 0.158 & 0.15 & 5.06 & 0.2 & 26.58 \\
\hline Mean Pitch $\left(\theta_{\mathrm{m}}, \operatorname{deg}\right)$ & 3.56 & 0.86 & 75.84 & 2.67 & 25.00 \\
\hline Average of Pitch Amp. $\left(\theta_{\mathrm{amp}}, \mathrm{deg}\right)$ & 3.15 & 4.86 & 54.29 & 5.95 & 88.89 \\
\hline CG Acceleration Amp. $\left(\eta_{\mathrm{CG}}, \mathrm{g}\right)$ & 0.68 & 0.87 & 27.94 & 1.01 & 48.53 \\
\hline
\end{tabular}

Table 13- Regular waves studies for the most probable condition of irregular waves for light weight configuration and comparison with EFD irregular waves results

\begin{tabular}{|c|c|c|c|c|c|}
\hline \multirow[b]{2}{*}{ Parameter } & \multirow[b]{2}{*}{ EFD, Irregular } & \multicolumn{2}{|c|}{$\mathrm{LCG}=57.7 \% \mathrm{~L}$} & \multicolumn{2}{|c|}{$\mathrm{LCG}=63 \% \mathrm{~L}$} \\
\hline & & $\begin{array}{l}\text { CFD, Regular, } \\
\text { Most Probable }\end{array}$ & $\begin{array}{l}\text { Difference } \\
(\mathrm{d} \% \mathrm{D})\end{array}$ & $\begin{array}{l}\text { CFD, Regular, } \\
\text { Most Probable }\end{array}$ & $\begin{array}{l}\text { Difference } \\
(\mathrm{d} \% \mathrm{D})\end{array}$ \\
\hline$\lambda_{\mathrm{p}} / \mathrm{L}$ & \multicolumn{5}{|c|}{2.788} \\
\hline$a_{p} / L$ & \multicolumn{5}{|c|}{0.0545} \\
\hline $\mathrm{H}_{\mathrm{p}} / \lambda_{\mathrm{p}}$ & \multicolumn{5}{|c|}{$1 / 26$} \\
\hline Added Resistance $\left(\mathrm{R}_{\mathrm{AW}} / \Delta\right)$ & 0.095 & 0.1 & 5.2 & 0.132 & 38.9 \\
\hline $\begin{array}{l}\text { Average of Resistance Amp. } \\
\qquad\left(\mathrm{R}_{\mathrm{W}} / \Delta\right)\end{array}$ & 0.242 & 0.223 & 7.8 & 0.19 & 21.5 \\
\hline Mean Heave $\left(z_{\mathrm{m}} / \mathrm{b}\right)$ & 0.069 & 0.069 & 0.4 & 0.15 & 117.4 \\
\hline Average of Heave Amp. $\left(\mathrm{z}_{\mathrm{amp}} / \mathrm{b}\right)$ & 0.159 & 0.168 & 5.6 & 0.239 & 42.3 \\
\hline Mean Pitch $\left(\theta_{\mathrm{m}}, \mathrm{deg}\right)$ & 3.63 & 2.988 & 17.7 & 5.65 & 55.6 \\
\hline Average of Pitch Amp. $\left(\theta_{\mathrm{amp}}, \mathrm{deg}\right)$ & 3.27 & 4.74 & 44.9 & 5.52 & 68.8 \\
\hline CG Acceleration Amp. $\left(\eta_{\mathrm{CG}}, \mathrm{g}\right)$ & 0.99 & 1.07 & 8.1 & 1.05 & 6.1 \\
\hline
\end{tabular}

Table 14- Statistical analysis of irregular waves simulation results for heavy and light weight configurations

\begin{tabular}{|c|c|c|c|c|c|}
\hline & & \multicolumn{2}{|c|}{ Irregular Waves } & Most Probable Regular Waves \\
\hline Parameter & Condition & EV & SD\%|EV| & E\%EV & E\%SD \\
\hline \multirow{2}{*}{$\mathrm{C}_{\mathrm{t}}\left(\times 10^{3}\right)$} & Heavy Weight & 8.433 & 56.73 & 1.22 & 6.55 \\
\cline { 2 - 6 } & Light Weight & 8.805 & 89.04 & 15.96 & 16.74 \\
\hline \multirow{2}{*}{$\mathrm{z} / \mathrm{L}\left(\times 10^{3}\right)$} & Heavy Weight & 0.534 & 43.34 & 162.32 & 35.51 \\
\cline { 2 - 6 } & Light Weight & 0.554 & 43.74 & 21.73 & 17.91 \\
\hline \multirow{2}{*}{$\theta(\mathrm{deg})$} & Heavy Weight & 3.69 & 42.91 & 55.76 & 18.74 \\
\cline { 2 - 6 } & Light Weight & 4.02 & 41.15 & 18.65 & 39.73 \\
\hline
\end{tabular}


Table 15- Validation of irregular waves simulations for heavy and light weight configurations

\begin{tabular}{|c|c|c|c|c|}
\hline Parameter & Condition & EFD & CFD & E\%D \\
\hline \multirow{2}{*}{ Calm Water Resistance $(\mathrm{R} / \Delta)$} & Heavy Weight & 0.192 & 0.227 & 18.45 \\
\cline { 2 - 5 } & Light Weight & 0.147 & 0.2 & 36.1 \\
\hline \multirow{2}{*}{ Added Resistance $\left(\mathrm{R}_{\mathrm{AW}} / \Delta\right)$} & Heavy Weight & 0.085 & 0.084 & 1.15 \\
\cline { 2 - 5 } & Light Weight & 0.095 & 0.078 & 17.89 \\
\hline \multirow{2}{*}{ Average of Resistance Amp. $\left(\mathrm{R}_{\mathrm{W}} / \Delta\right)$} & Heavy Weight & 0.277 & 0.248 & 10.55 \\
\cline { 2 - 5 } & Light Weight & 0.242 & 0.22 & 9.09 \\
\hline \multirow{2}{*}{ Mean Heave $\left(\mathrm{z}_{\mathrm{m} .} / \mathrm{b}\right)$} & Heavy Weight & 0.052 & 0.046 & 11.54 \\
\cline { 2 - 5 } & Light Weight & 0.069 & 0.068 & 1.83 \\
\hline \multirow{2}{*}{ Average of Heave Amp. $\left(\mathrm{z}_{\mathrm{amp}} / \mathrm{b}\right)$} & Heavy Weight & 0.158 & 0.143 & 9.49 \\
\cline { 2 - 5 } & Light Weight & 0.159 & 0.15 & 5.66 \\
\hline \multirow{2}{*}{ Mean Pitch $\left(\theta_{\mathrm{m}}, \mathrm{deg}\right)$} & Heavy Weight & 3.56 & 3.21 & 9.83 \\
\cline { 2 - 5 } & Light Weight & 3.63 & 3.42 & 5.73 \\
\hline \multirow{2}{*}{ Average of Pitch Amp. $\left(\theta_{\mathrm{amp}}, \mathrm{deg}\right)$} & Heavy Weight & 3.15 & 2.95 & 6.35 \\
\cline { 2 - 5 } & Light Weight & 3.27 & 3.28 & 0.26 \\
\hline \multirow{2}{*}{ Acceleration Amp. $\left(\eta_{\mathrm{CG}}, \mathrm{g}\right)$} & Heavy Weight & 0.68 & 0.69 & 1.47 \\
\cline { 2 - 5 } & Light Weight & 0.99 & 1.0 & 1.01 \\
\hline
\end{tabular}

Table 16- Statistical analysis of slamming waves and loads at probe B2 for irregular waves simulations with heavy and light weight configurations. Pressure values are scaled up for a $\mathrm{L}=10 \mathrm{~m}$ full scale ship.

\begin{tabular}{|c|c|c|c|c|c|}
\hline \multirow{2}{*}{ Parameter } & \multirow{2}{*}{ Condition } & \multicolumn{2}{|c|}{ Slamming Wave } & \multicolumn{2}{c|}{ Slamming Load (KPa) } \\
\cline { 3 - 6 } & & $\mathrm{T}(\mathrm{s})$ & $\mathrm{H}(\mathrm{m})$ & Emerging & Re-entering \\
\hline \multirow{2}{*}{$\mathrm{N}$} & Heavy Weight & \multicolumn{2}{|c|}{37} & 20 & 19 \\
\cline { 2 - 6 } & Light Weight & \multicolumn{2}{|c|}{61} & 71 & 71 \\
\hline \multirow{2}{*}{$\mathrm{EV}$} & Heavy Weight & 4.47 & 1.02 & -18.39 & 30.98 \\
\cline { 2 - 6 } & Light Weight & 4.41 & 0.97 & -16.61 & 45.79 \\
\hline \multirow{2}{*}{$\mathrm{SD}$} & Heavy Weight & 1.23 & 0.53 & 6.71 & 14.62 \\
\cline { 2 - 6 } & Light Weight & 1.14 & 0.54 & 5.52 & 25.12 \\
\hline \multirow{2}{*}{$\mathrm{SD} \%|\mathrm{EV}|$} & Heavy Weight & 27.43 & 52.12 & 36.49 & 47.19 \\
\cline { 2 - 6 } & Light Weight & 25.93 & 55.16 & 33.20 & 54.86 \\
\hline \multirow{2}{*}{ Max } & Heavy Weight & 6.4 & 2.61 & -28.64 & 51.74 \\
\cline { 2 - 6 } & Light Weight & 6.6 & 2.85 & -28.43 & 167.51 \\
\hline
\end{tabular}




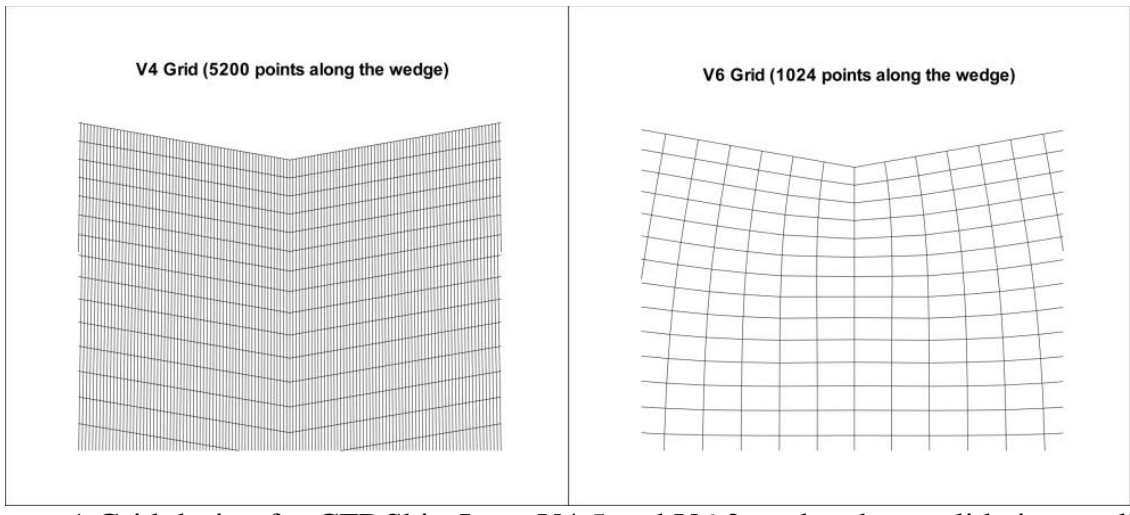

Figure 1 Grid design for CFDShip-Iowa V4.5 and V6.2 wedge drop validation studies

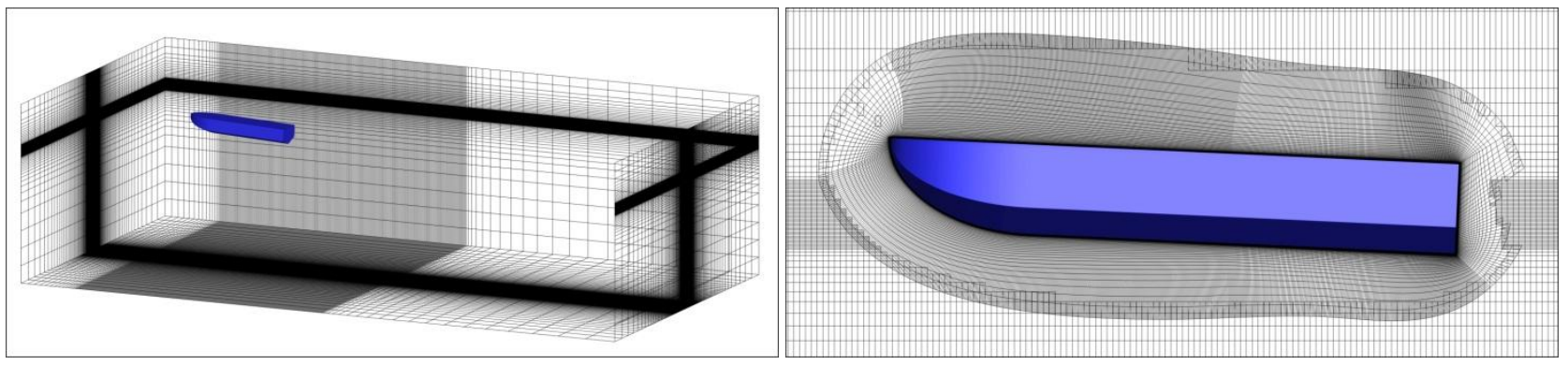

Figure 2 Grid design and geometry for Fridsma prismatic planing hull with constant deadrise of $20^{\circ}$ and $\mathrm{L} / \mathrm{b}=4$ used in CFDShip-Iowa V4.5 validation studies 


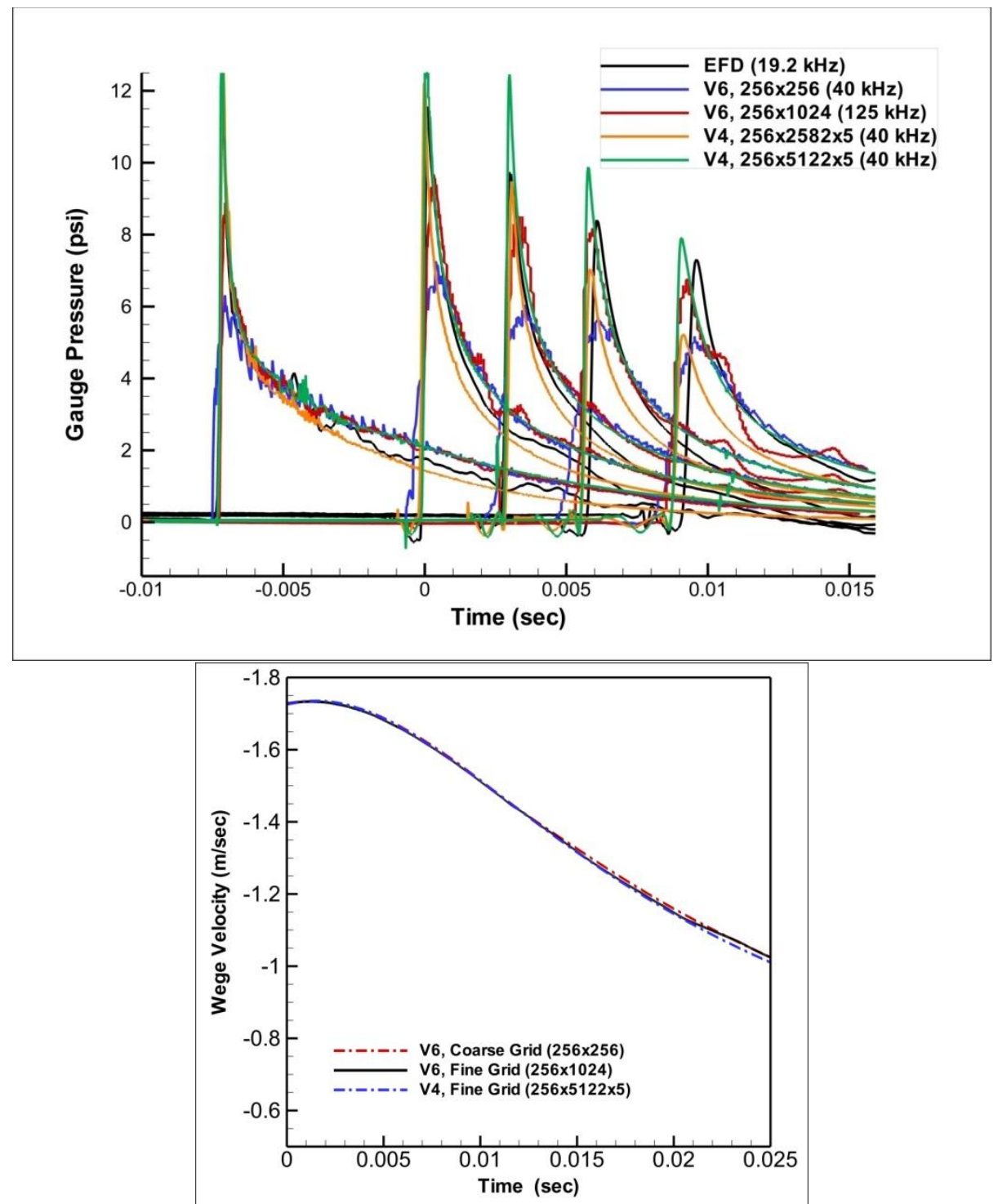

Figure 3 CFDShip-Iowa V4.5 and V6.2 wedge drop validation results for pressure time histories at 5 probes 


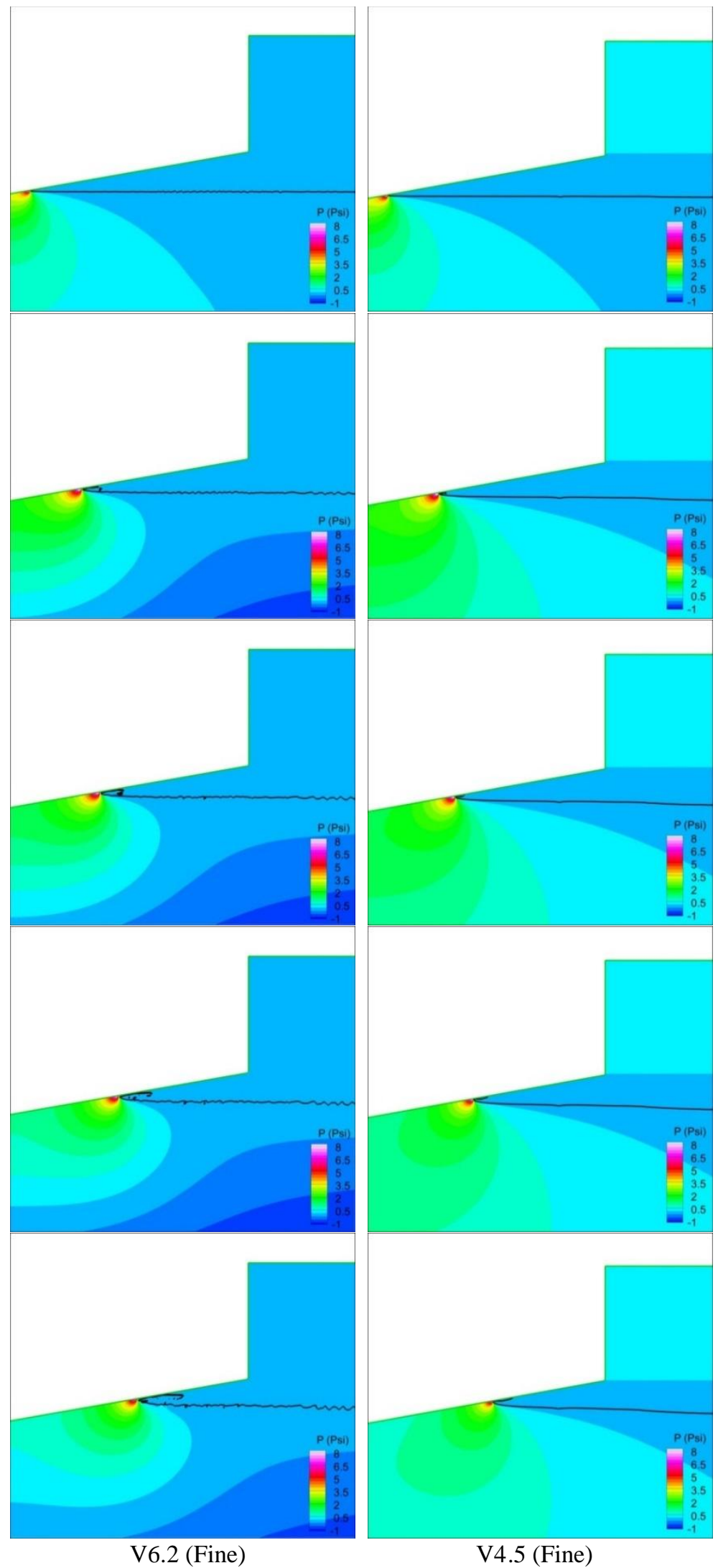

Figure 4 Pressure contours and free surface profile at the 5 probe locations for CFDShip-Iowa wedge drop simulations 

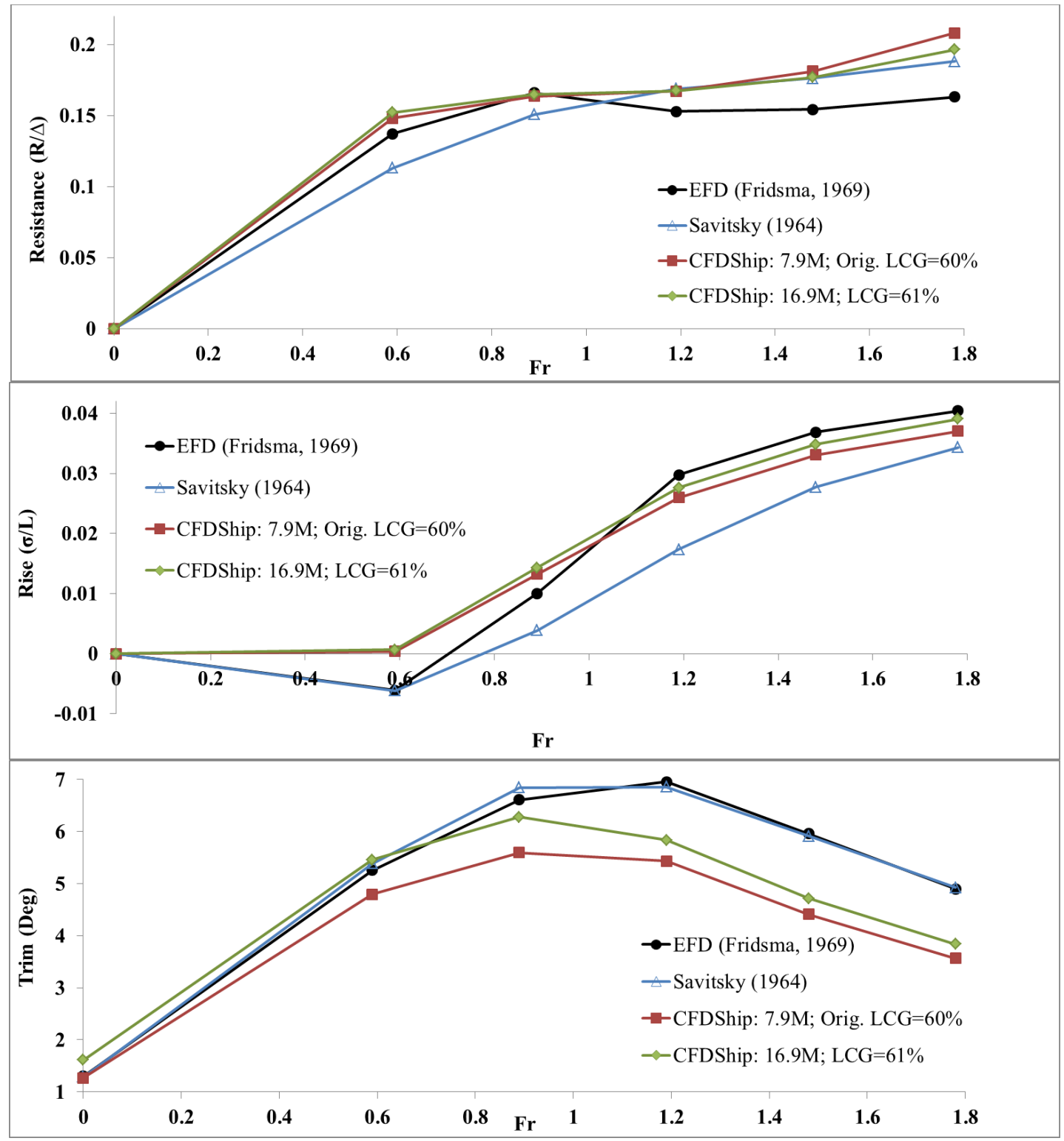

Figure 5 Validation results for calm deep water free to sinkage and trim CFDShip-Iowa simulations over the whole range of Fr including LCG sensitivity and grid size studies and comparison with Savitsky parametric equations

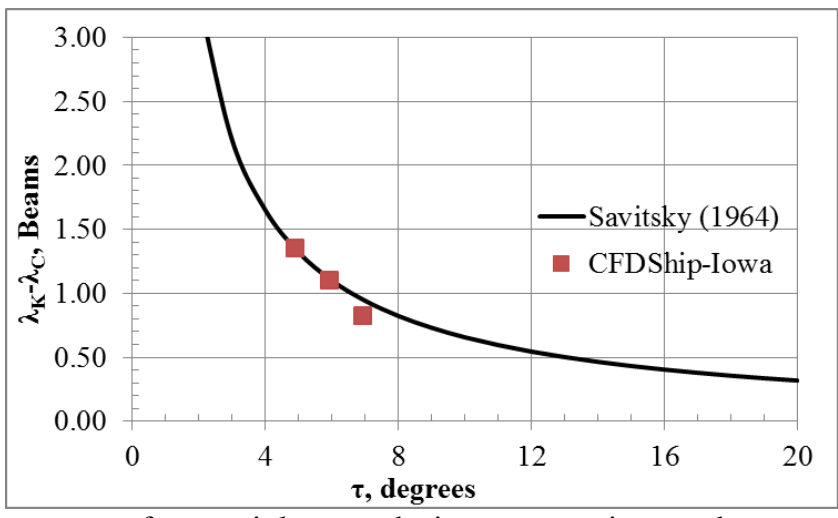

Figure 6 Wave rise for calm deep water free to sinkage and trim computations and comparison with empirical expression 


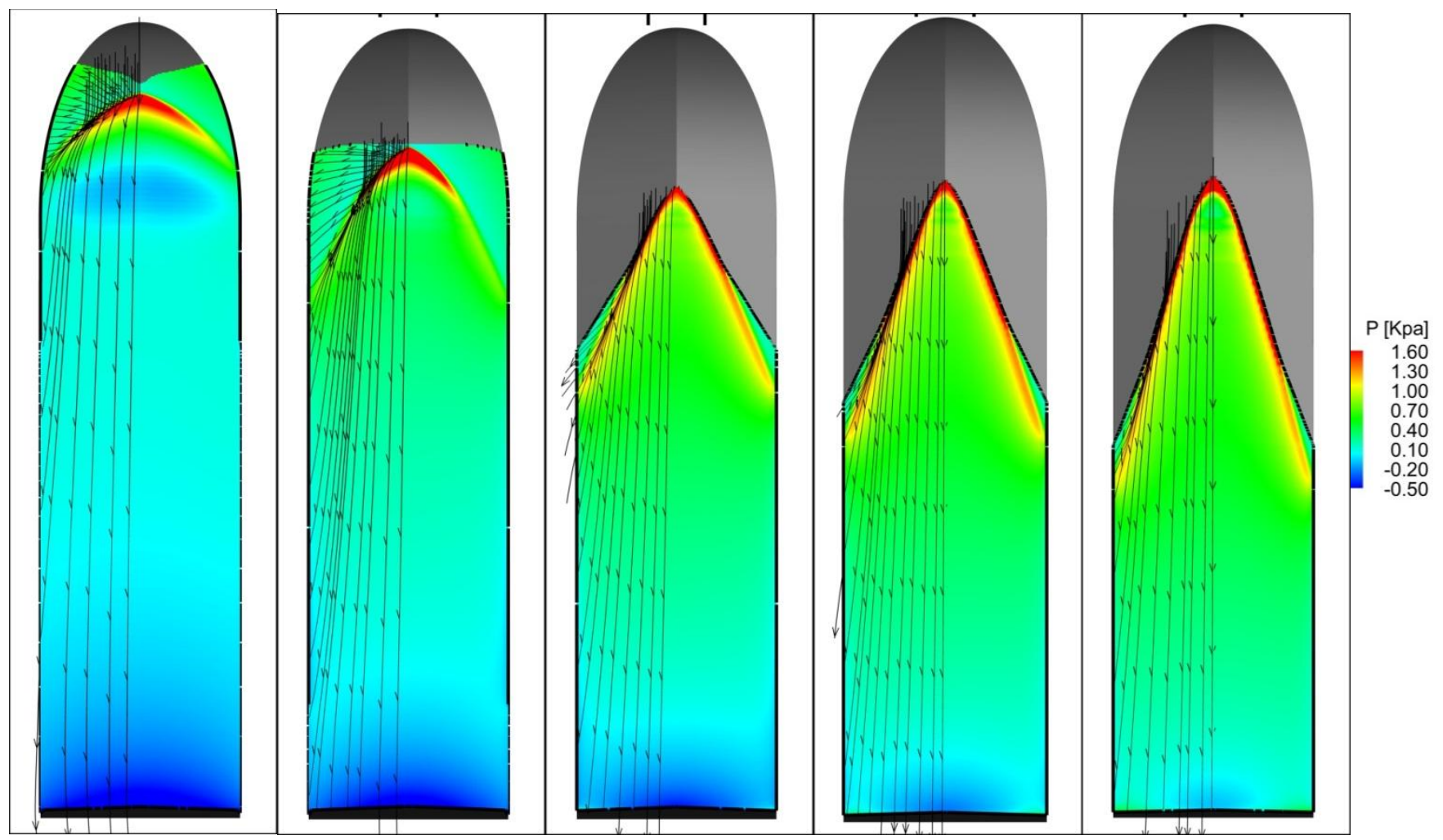

Figure 7 Hull pressure distribution (model scale, $\mathrm{L}=0.9144 \mathrm{~m}$ ) and surface streamlines showing flow direction along the hull and extent of spray area for calm deep water free to sinkage and trim simulations at $\mathrm{Fr}=0.59,0.89,1.19,1.48,1.78$ (left to right)

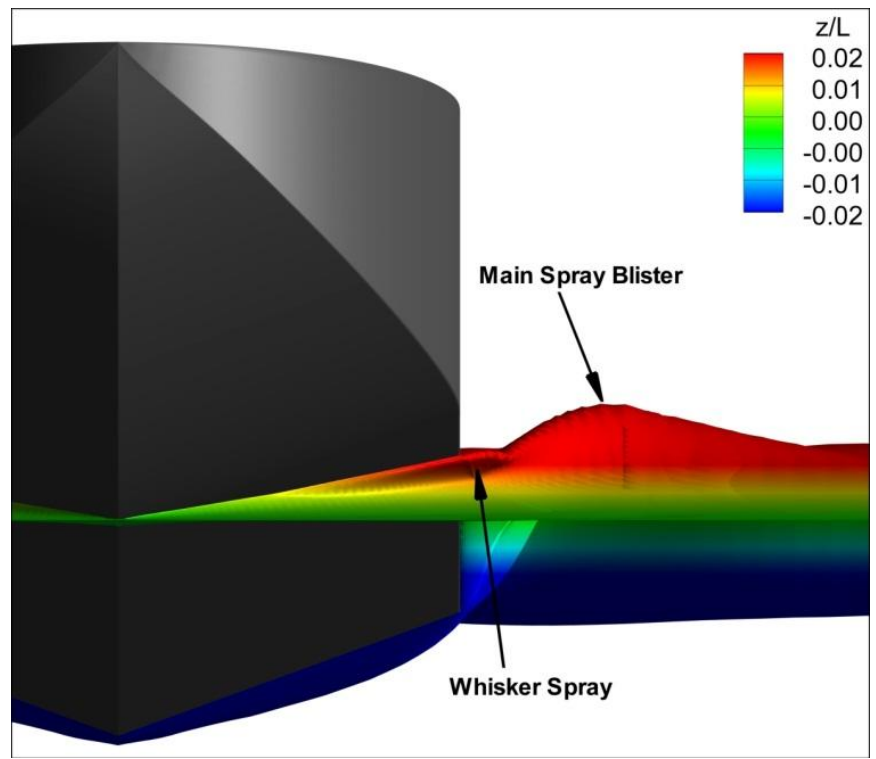

Figure 8 Spray components shown for calm deep water free to sinkage and trim computation at $\mathrm{Fr}=1.19$ 

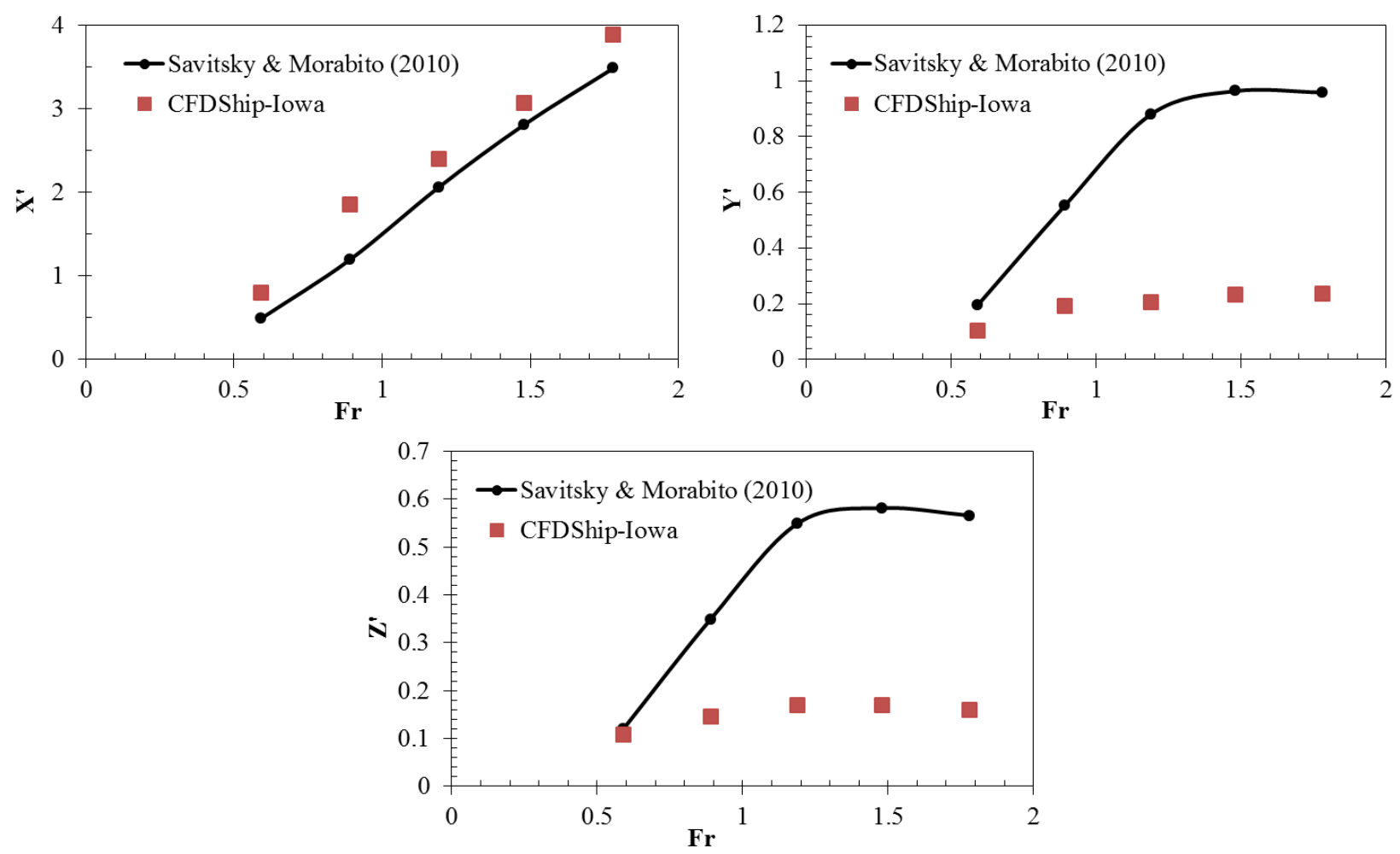

Figure 9 Magnitude and location of maximum main spray height for calm deep water free to sinkage and trim computations compared with empirical expression

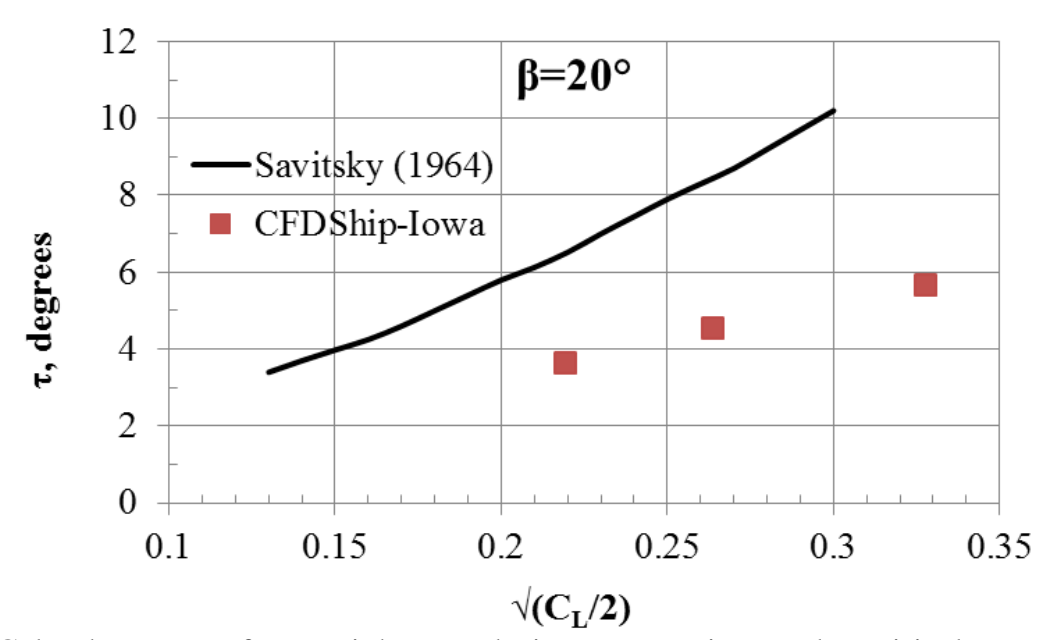

Figure 10 Calm deep water free to sinkage and trim computations and empirical porpoising limits 


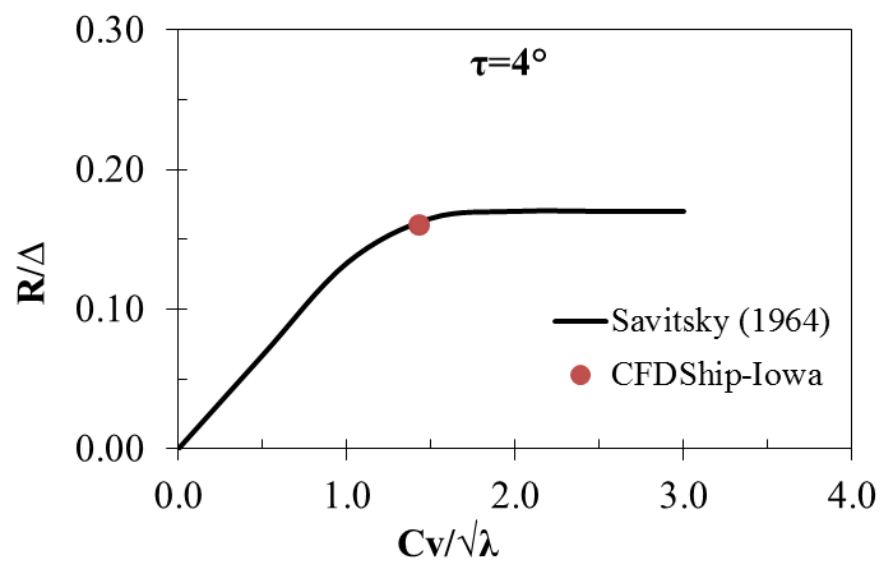

Figure 11 Drag-lift ratio vs. speed coefficient for calm deep water with fixed sinkage and trim at $\tau=4^{\circ}$ and comparison with empirical expression

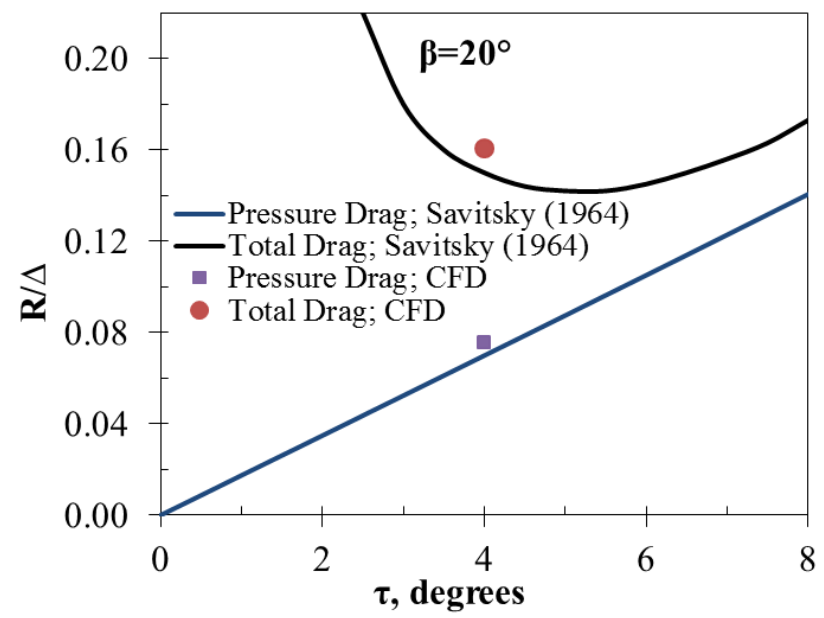

Figure 12 Drag-lift ratio vs. trim angle for calm deep water with fixed sinkage and trim at $\tau=4^{\circ}$ and comparison with empirical expression

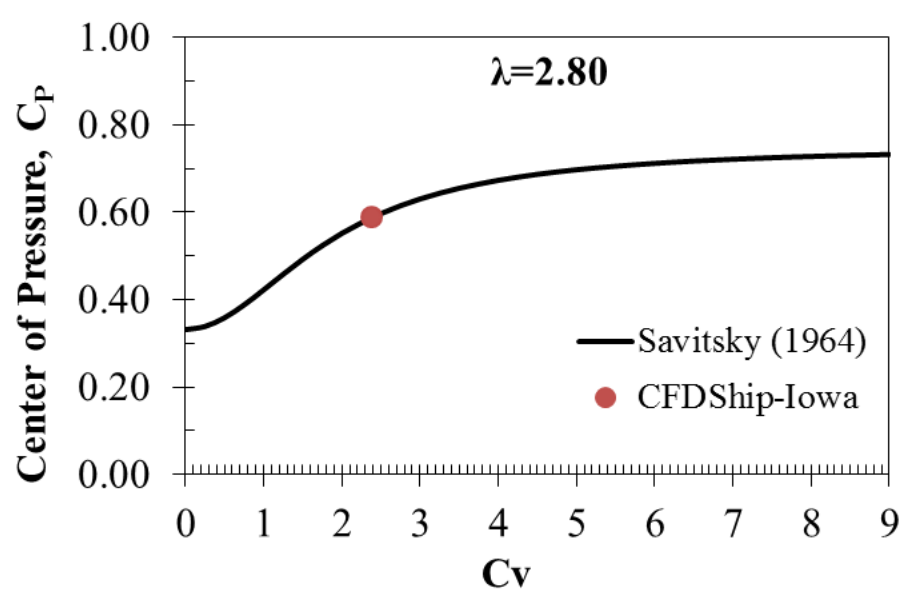

Figure 13 Center of pressure for calm deep water with fixed sinkage and trim at $\tau=4^{\circ}$ and comparison with empirical expression 


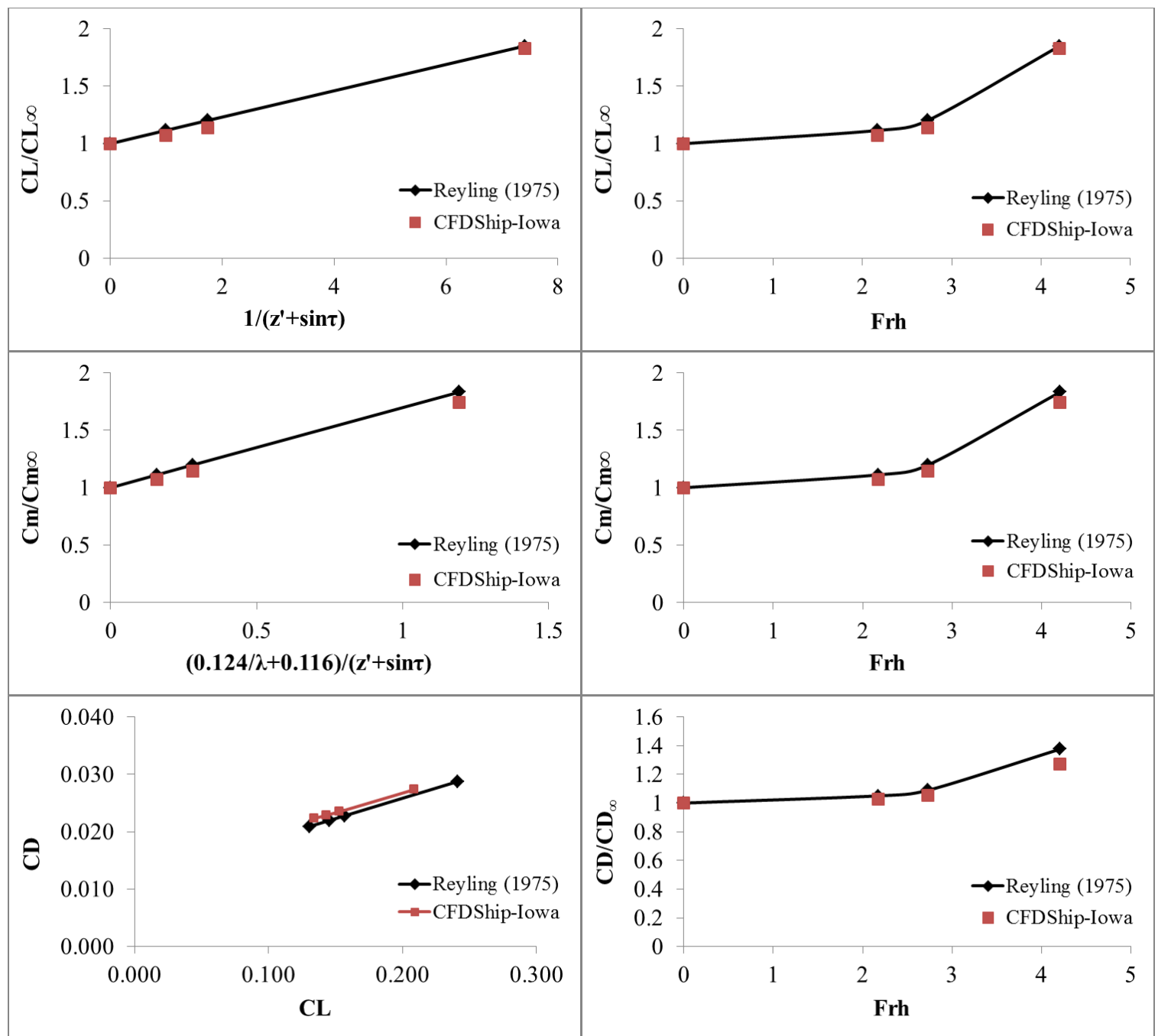

Figure 14 Validation for calm shallow water with fixed sinkage and trim at $\tau=4^{\circ}$

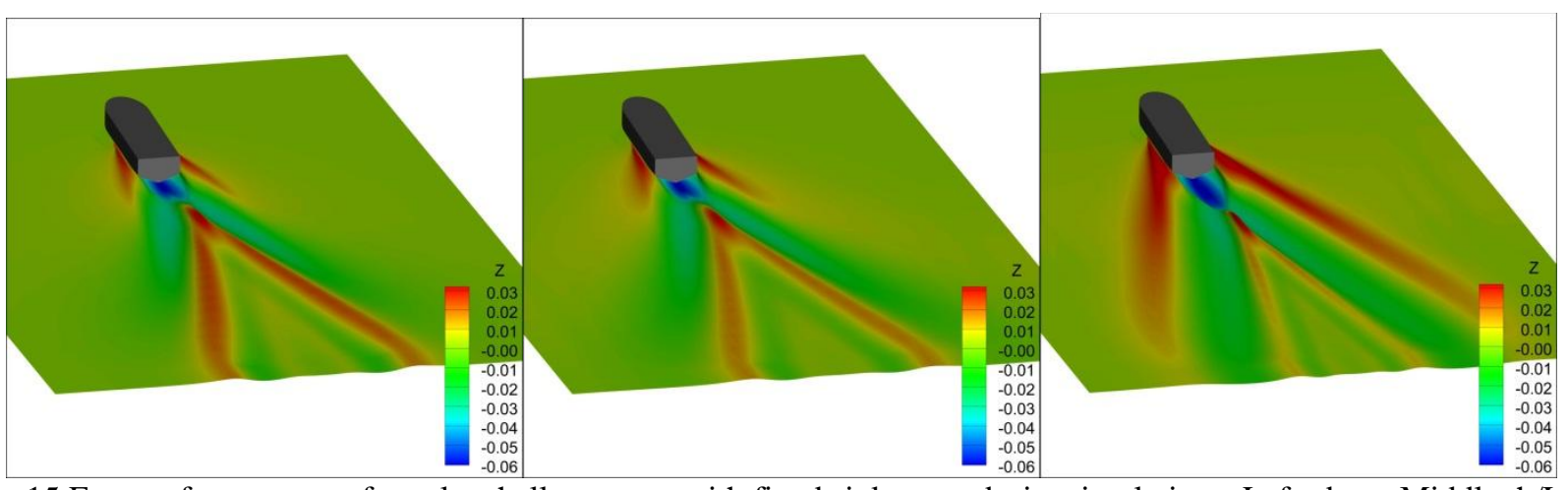

Figure 15 Free surface patterns for calm shallow water with fixed sinkage and trim simulations. Left: deep; Middle: $\mathrm{h} / \mathrm{L}=0.3$; Right: $\mathrm{h} / \mathrm{L}=0.08$ with no-slip bottom boundary condition 


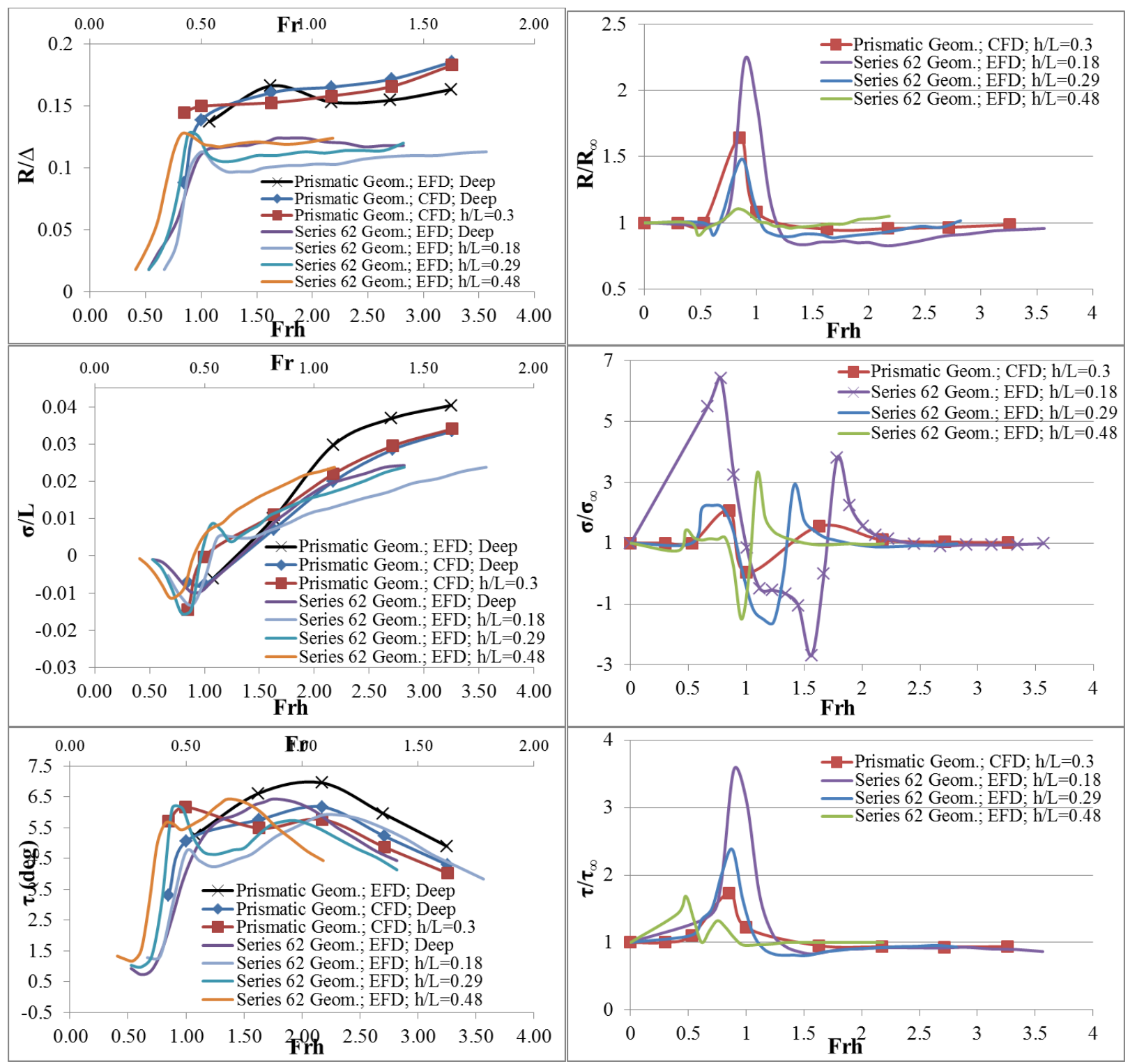

Figure 16 Results for calm shallow water free to sinkage and trim simulations at $\mathrm{h} / \mathrm{L}=0.3$ with very heavy configuration. EFD data are from [13] for prismatic geometry and [20] for Series 62 geometry. 

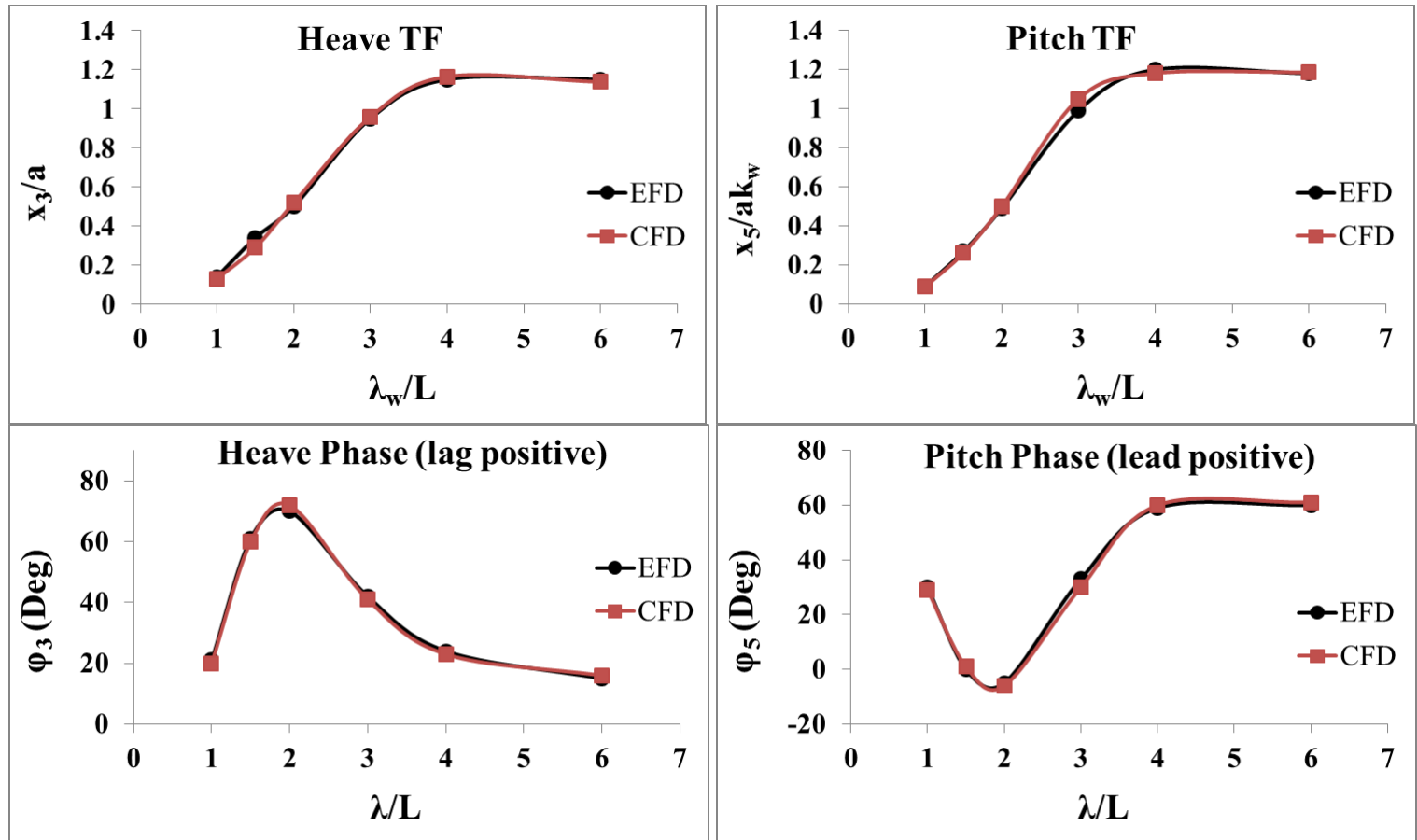

Figure 17 Regular head waves seakeeping validation at $\mathrm{Fr}=1.19$ on Grid\#8 (7.9M) vs. [13]
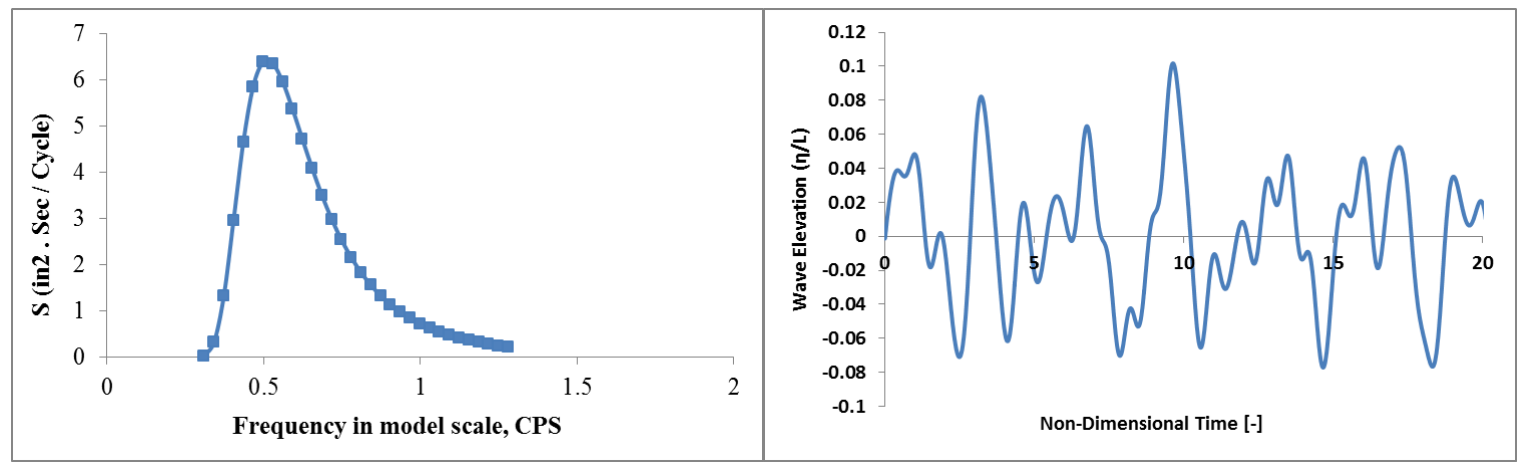

Figure 18 Irregular wave spectrum and time history of CFD reconstructed waves for irregular simulations 
Heavy Weight

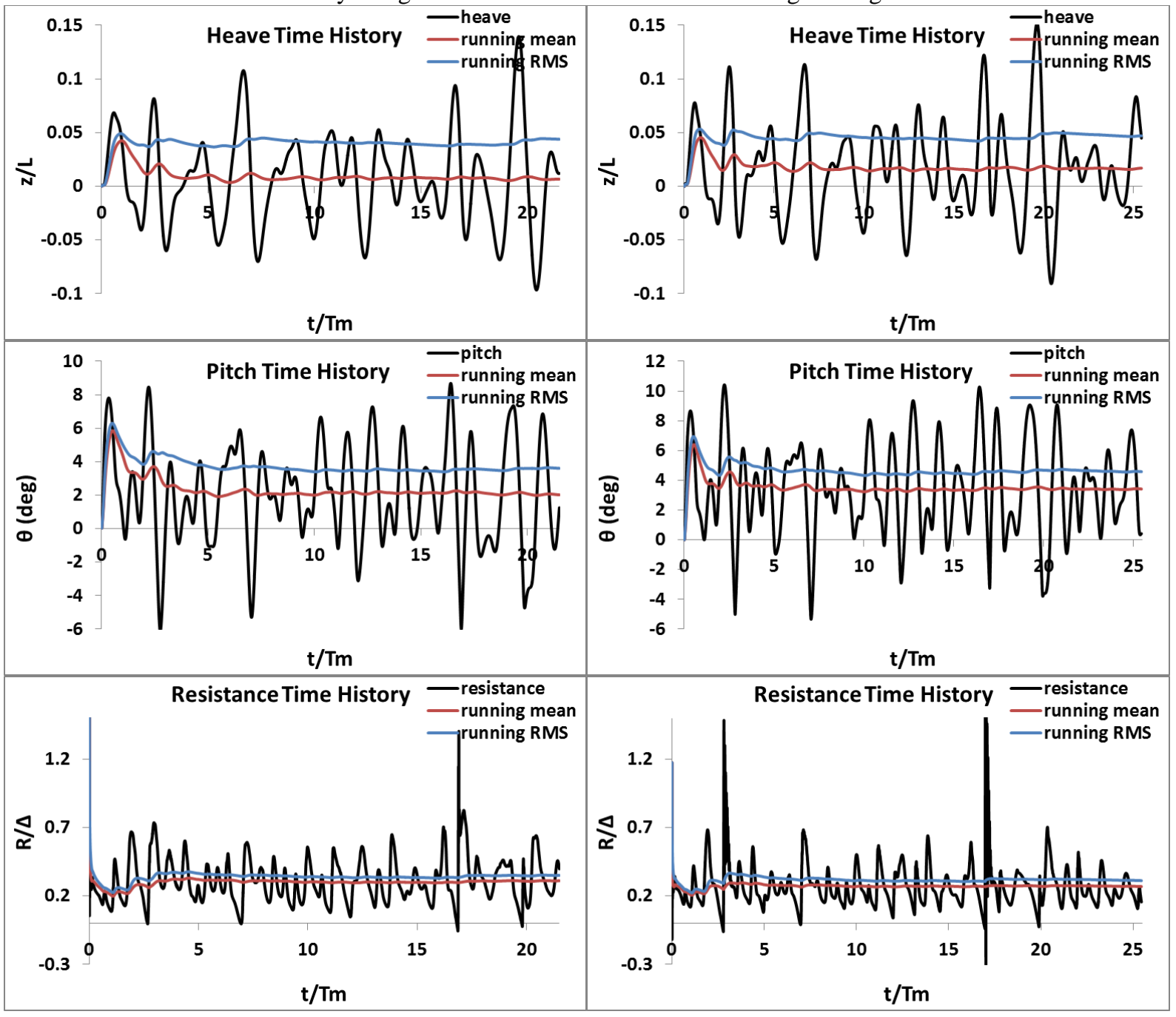

Figure 19 Time histories of CFD results for irregular waves simulations with heave and light weight configurations 


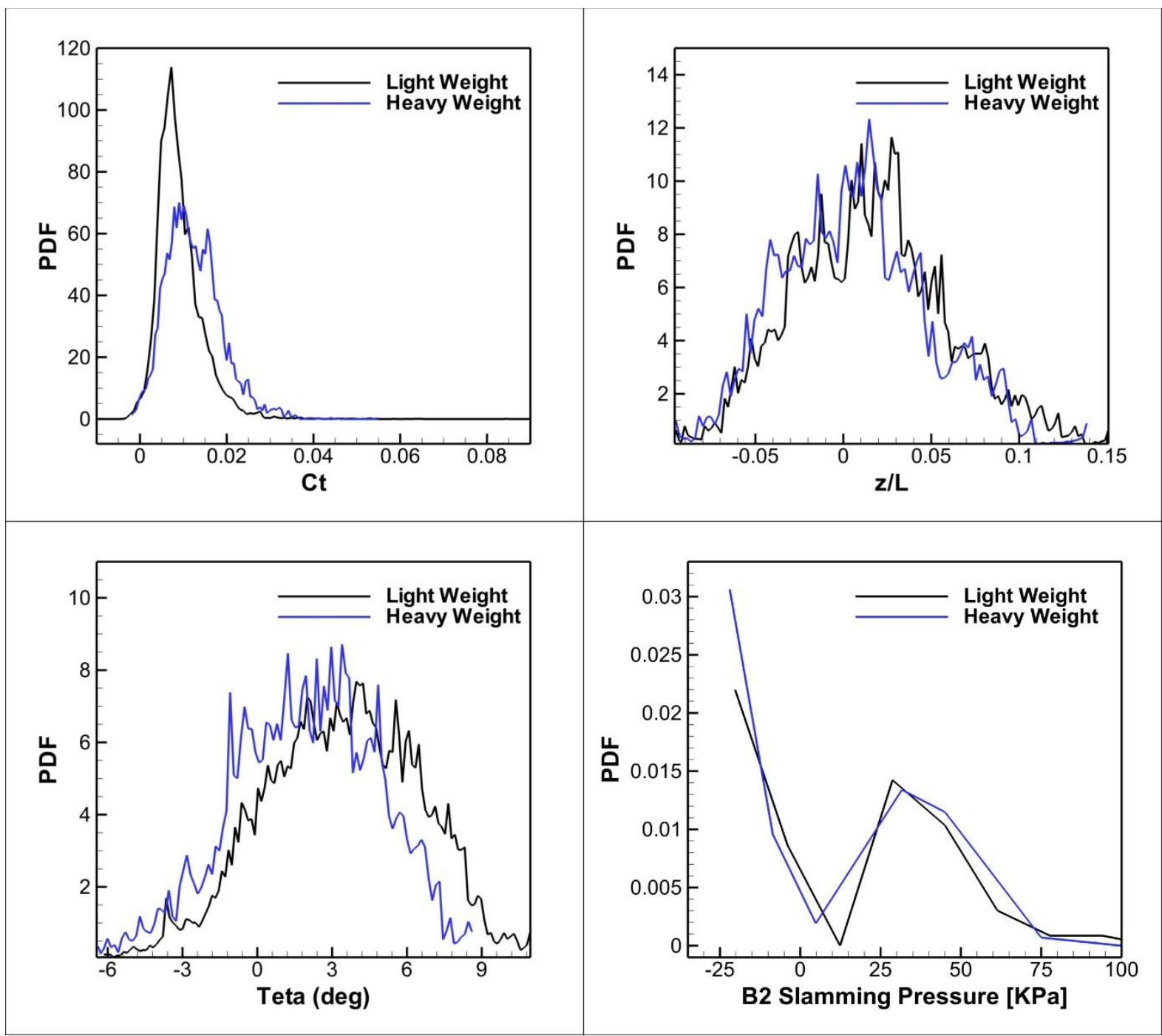

Figure 20 Time history PDF for resistance coefficient, motions, and slamming pressure for irregular waves simulations with heave and light weight configurations. Pressure values are scaled up for a $\mathrm{L}=10 \mathrm{~m}$ full scale ship. 


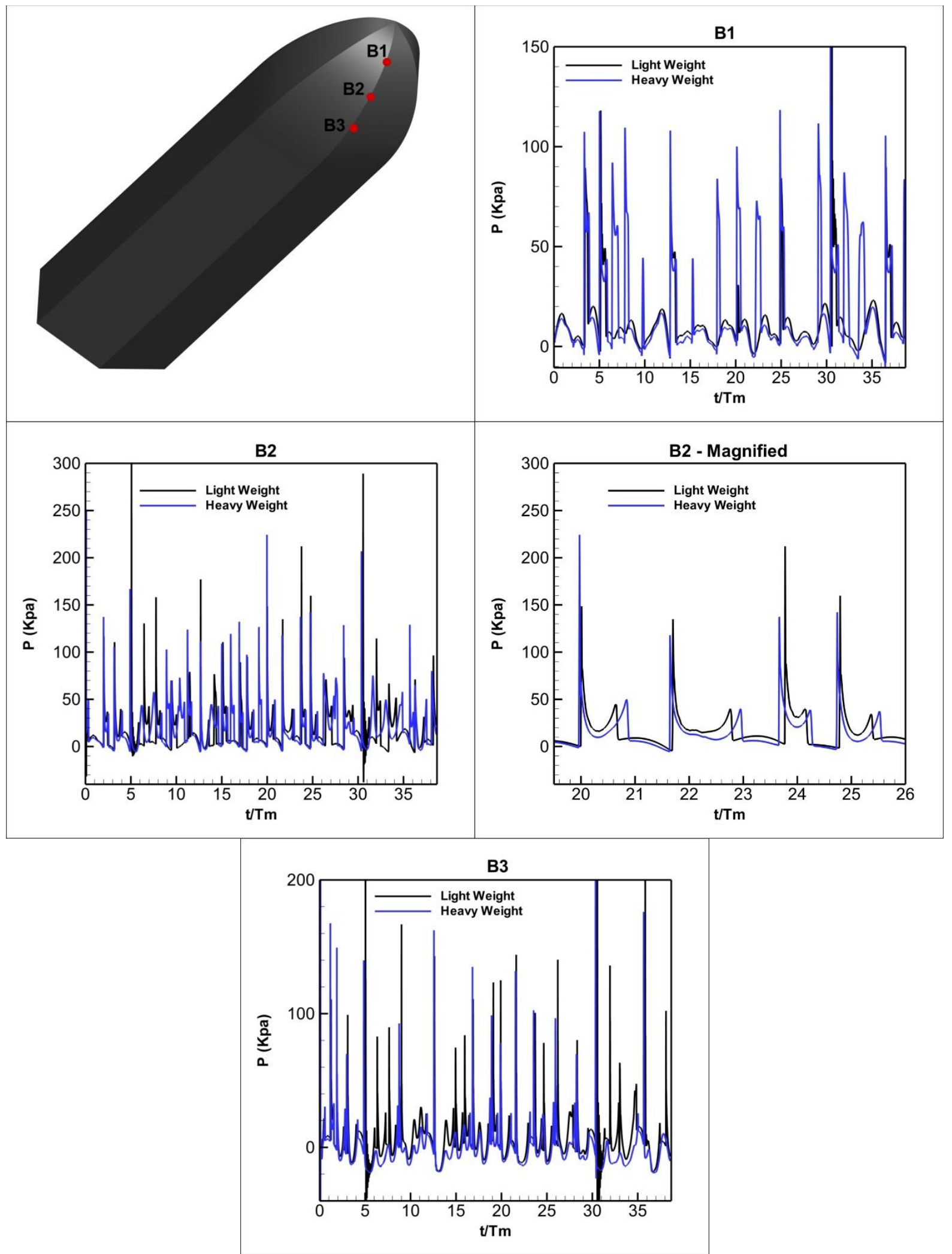

Figure 21 Slamming analysis for irregular waves simulations with heavy and light weight configurations. Pressure values are scaled up for a $\mathrm{L}=10 \mathrm{~m}$ full scale ship. 